\title{
Modeling Loss-of-Flow Accidents and Their Impact on Radiation Heat Transfer
}

\author{
Jivan Khatry and Fatih Aydogan \\ Center for Advanced Energy Studies (CAES), University of Idaho, 995 University Blvd., Idaho Falls, ID 83401, USA
}

Correspondence should be addressed to Fatih Aydogan; faydogan@gmail.com

Received 10 April 2017; Revised 19 July 2017; Accepted 14 August 2017; Published 31 October 2017

Academic Editor: Michael I. Ojovan

Copyright (C) 2017 Jivan Khatry and Fatih Aydogan. This is an open access article distributed under the Creative Commons Attribution License, which permits unrestricted use, distribution, and reproduction in any medium, provided the original work is properly cited.

\begin{abstract}
Long-term high payload missions necessitate the need for nuclear space propulsion. The National Aeronautics and Space Administration (NASA) investigated several reactor designs from 1959 to 1973 in order to develop the Nuclear Engine for Rocket Vehicle Application (NERVA). Study of planned/unplanned transients on nuclear thermal rockets is important due to the need for long-term missions. In this work, a system model based on RELAP5 is developed to simulate loss-of-flow accidents on the Pewee I test reactor. This paper investigates the radiation heat transfer between the fuel elements and the structures around it. In addition, the impact on the core fuel element temperature and average core pressure was also investigated. The following expected results were achieved: (i) greater than normal fuel element temperatures, (ii) fuel element temperatures exceeding the uranium carbide melting point, and (iii) average core pressure less than normal. Results show that the radiation heat transfer rate between fuel elements and cold surfaces increases with decreasing flow rate through the reactor system. However, radiation heat transfer decreases when there is a complete LOFA. When there is a complete LOFA, the peripheral coolant channels of the fuel elements handle most of the radiation heat transfer. A safety system needs to be designed to counteract the decay heat resulting from a post-LOFA reactor scram.
\end{abstract}

\section{Introduction}

A nuclear thermal rocket (NTR) is a nuclear fission propelled vehicle that travels into space for long-term space missions. Typically, NTRs have open-cycle reactor designs and consist of a propellant tank, pump, and reactor vessel. The reactor core serves as the engine of the rocket and heats the coolant (also known as propellant or working fluid) and then releases it at an exhaust pressure. The reactor vessel of the NTR houses the core barrel, neutron reflector, control drum mechanisms, and core support plates/structures. Instead of control rods, NTRs have control drums to control the reactivity. These are rotated in order to keep the reactor critical.

Historically, NTRs have used various propellants, such as ammonia, nitrogen, and hydrogen. The KIWI reactors of the Los Alamos Scientific Laboratory (LASL) and the Tory reactors of the Lawrence Livermore Laboratories used ammonia and nitrogen, respectively. The Rocketdyne Division of North American Aviation identified hydrogen as a more suitable propellant than ammonia and nitrogen [1].
The payload is the mass of the rocket/vehicle minus the mass of the structure and the mass of the propellant. Hence, it is basically the mass of the cargo or crew that the vehicle is carrying. NTRs need less fuel per payload than chemical combustion rockets. In addition, they can diminish travel time and cut down on risks to near-earth objects and Mars [2]. NASA anticipates that NTRs can travel to Mars by taking $50 \%$ of the time envisioned [3]. The learning experience from NTR studies can be used in improving the design of terrestrial nuclear reactors, especially safety systems.

Aside from NTRs, nuclear electric fission rockets (NEFRs) have also been devised. In contrast to NTRs, these have similar fundamentals to those of terrestrial nuclear power plants, such as a reactor core, an energy conversion system, and a heat rejection system. NEFRs generate electricity for the vehicular instruments and the electric propulsion system. The following NEFRs have operated in space: (i) the BUK and TOPAZ reactors of Russia and (ii) the SNAP-10A reactor of the United States [4]. Nuclear reactors for space exploration have some design criteria that are 
distinct from those of terrestrial nuclear reactors. According to De Grandis et al. [5] and Finzi et al. [6], nuclear reactors of this kind have the following design criteria: (i) they produce the required electrical power (relevant for NEFRs), (ii) they need to last for the required time period sans human intervention and refueling, (iii) they have limited mass and volume of design due to payload, (iv) they meet safety requirements of the terrestrial nuclear reactors, (v) they need less maintenance and repair procedures than terrestrial reactors, and (vi) they prevent leakage of fluids and possess safety systems to address these. Summerer and Stephenson [4] list the following design criteria: (i) sufficient efficiency concerning heat removal in space and launch environments, (ii) very small and compact reactor cores, (iii) very high enrichment ratios, (iv) high core temperatures, and (v) low core power densities to enable long usage times.

The Nuclear Engine for Rocket Vehicle Application (NERVA) investigated several NTR designs from 1959 to 1973. The first NTR design developed was the KIWI B4D in 1964. The last NTR design developed was Nuclear Furnace-1. Aside from these, prototype designs of NTRs include NRX, Phoebus, Pewee, and XE Prime. Out of these designs, Pewee had the highest operating temperature of approximately $2500 \mathrm{~K}$ and Nuclear Furnace-1 had the longest reactor operation time of approximately 160 minutes [7].

Several transients, whether intended or unintended, have been experimented with/simulated on nuclear space reactors. In the following paragraphs, we present some examples of transients that have been studied.

Peoples [8] computationally studied transients of the following: (a) control drum run-in, (b) decrease of coolant flow, (c) decrease of coolant inlet temperature, and (d) a lossof-coolant accident (LOCA) on a lithium-cooled space power fast-spectrum reactor. In particular, computer programs such as FORE and the Continuous System Modeling Program (CSMP) were used for the reactivity and flow rate transients, respectively. For part (a), the reactivity insertion accident due to run-in of the control drums is not a major issue as long as the reactivity insertion rates are restricted to a safety margin less than $\$ 0.097 / \mathrm{s}$. For part (b), the reactor can operate at a lithium flow rate $90 \%$ less than the standard steady-state flow rate as long as the fuel element temperature does not reach/exceed $1388.89^{\circ} \mathrm{K}$. For part (c), a safety margin of 40 seconds is necessary to respond to a transient where the lithium inlet temperature is $116.67^{\circ} \mathrm{K}$ less than the normal steady-state conditions. For part (d), a large emergency lithium supply is needed to remove the decay heat and prevent meltdown of the core.

According to Kruger [9], experiments such as a burst transient, an irradiation transient, and a fuel flow transient were carried out at the Transient Reactor Test (TREAT) facility. This work demonstrated that cermet fuel has favorable thermal and mechanical properties and can withstand severe transients.

Akyuzlu [2] developed a 1D mathematical model to simulate thermal-hydrodynamic transients in the cooling channels of a nuclear thermal propulsion engine. Schmidt et al. [10] used a computer code known as KINETIC to study flow and heat transfer transients associated with a
Particle Bed Reactor- (PBR-) based NTR. KINETIC code is based on the point reactor model and has nodes to describe fluid dynamics and heat transfer mechanisms. The broad range of the KINETIC code includes nucleonics, hydraulics, heat transfer, control rods, turbo-pump assemblies, valves, and nozzles. Schmidt et al. [10] concluded that KINETIC is a suitable transient analysis algorithm to investigate startup and shutdown profiles of PBR-based NTR designs. In addition, KINETIC can be used to assess turbo-pump assembly start strategies, modify the design of the reactor for the purpose of reducing feedback, and also assess engine shutdown strategies.

The purpose of this work is to investigate the impact of loss-of-flow accident (LOFA) on the radiation heat transfer in the NTR core. This is a behavior that has not been studied by those who have studied "flow rate change transients" in nuclear rocket systems. In addition, the impact on the fuel element temperature and the pressure profile in the core will also be noted. Here, it is assumed that the rocket was in normal operation and then, all of a sudden, a LOFA occurred due to the reactor pump failure. Here, the Pewee I test reactor has been selected for this study. The Reactor Excursion Leak Analysis Program (RELAP), a thermal hydraulics code developed at the Idaho National Laboratory, has been selected to model the Pewee I test reactor.

The following sections will be presented in this work: (i) a detailed description of the Pewee I test reactor, (ii) a brief description of the Pewee I RELAP model, (iii) results and discussion from the LOFA trials, and (iv) a conclusion to summarize the major findings of this work.

\section{Description of the Pewee I Test Reactor}

2.1. General Background on Pewee I. The Pewee I test reactor was a design that had $25 \%$ of the fuel elements of the Phoebus design. It was constructed to examine the fuel elements of the latter. Pewee I never operated in space [13]. The Phoebus design was constructed under Project Rover, which was a joint project managed by Atomic Energy Commission, Los Alamos Scientific Laboratory (LASL), and NASA. The Copernicus Spacecraft, designed by NASA to take humans to Mars in the 2030s, has been designed assuming that three Pewee-type engines are utilized. Pewee-type engines each have a thrust of $25000 \mathrm{klbf}$ [14].

\subsection{Design of Pewee and Thermal-Hydraulic Parameters.} Pewee I (Figure 1) primarily consists of the reactor pressure vessel and the exhaust nozzle. Bear in mind that Figure 1 assumes that Pewee $I$ is operating in space. Hence, the propellant tank and pump are presented. Please note that the propellant tank in reality is much larger than the reactor vessel and nozzle. Table 1 presents the dimensions concerning Pewee I.

2.3. Flow from the Propellant Tank. Figure 1 presents the coolant parameters across Pewee I with information such as mass flow rate $(W)$, pressure $(P)$, and temperature $(T)$. The numbers listed here are from Finseth [13]. The propellant tank holds all the propellant for the mission. The propellant in 


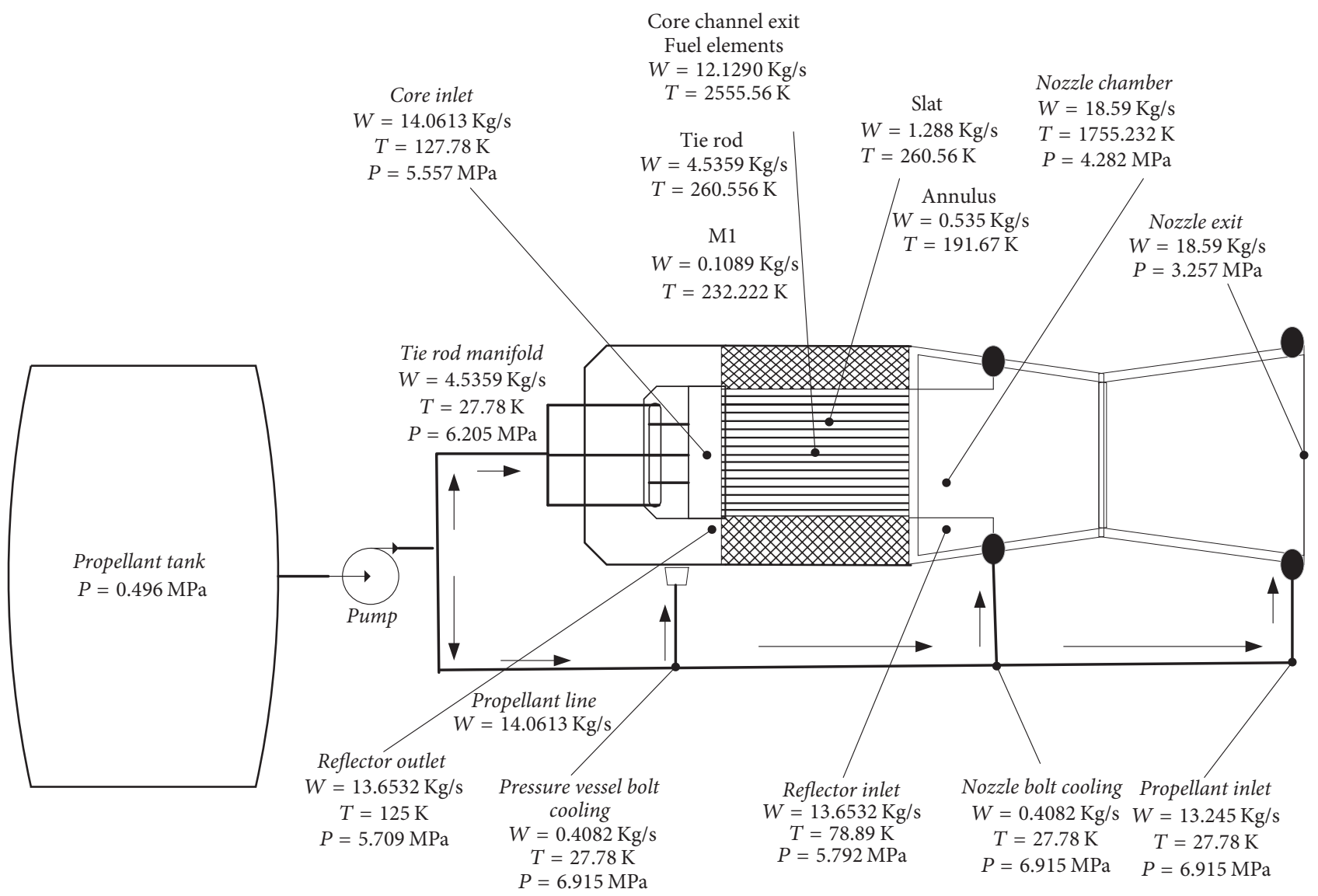

Figure 1: Pewee flow diagram (not drawn to scale).

TABle 1: Specifications of the Pewee I design.

\begin{tabular}{ll}
\hline Particulars & Details \\
\hline $\begin{array}{l}\text { Core diameter (m) } \\
\text { Ratio of support elements to fuel } \\
\text { elements }\end{array}$ & 0.53 \\
Number of fuel elements & $\begin{array}{l}402(390 \text { nineteen-hole type } \\
\text { and } 12 \text { twelve-hole type) }\end{array}$ \\
$\begin{array}{l}\text { Height of fuel elements (m) } \\
\text { Total uranium inventory in the }\end{array}$ & 1.32 \\
core (kg) & 36.42 \\
$\begin{array}{l}\text { Control drum diameters (m) } \\
\text { Reflector thickness (m) }\end{array}$ & 0.1 \\
$\begin{array}{l}\text { Aluminum support plate } \\
\text { thickness (m) }\end{array}$ & 0.20 \\
$\begin{array}{l}\text { Nozzle throat diameter (m) } \\
\text { Nozzle exit diameter }(\mathrm{m})\end{array}$ & 0.08 \\
\hline
\end{tabular}

this case is liquid hydrogen. Initially, at $0.5 \mathrm{MPa}$, the pump is used to raise the pressure of the liquid hydrogen to at least $6.92 \mathrm{MPa}$. From the pump, most of the flow enters the propellant line and the rest enters via the tie rod manifolds. From the propellant line, part of the flow goes to the pressure vessel bolt cooling, part of the flow goes to the nozzle bolt cooling, and the majority enters via the propellant inlet.
2.4. Propellant Tubes in Nozzle Wall, Nozzle Bolt Cooling, Reflector, and Pressure Vessel Bolt Cooling. There are 120 coolant tubes inside the shell of the nozzle chamber. The propellant travels via these tubes and it then mixes with the small portion of the propellant that enters via the nozzle bolt cooling. The propellant continues through an annular expansion region and then through the coolant holes of the beryllium reflector. The beryllium reflector is divided into both an inner and an outer reflector. The inner reflector has small coolant holes and the outer reflector has larger coolant holes. The outer reflector also houses the control drum cylinders with their poison plates for long-term reactivity control. Upon exiting the beryllium reflector, the propellant mixes with the coolant from the pressure vessel bolt cooling passage. The flow continues through the reactor vessel dome and then into the core.

2.5. Core of Pewee I. Within the core region shown in Figure 2, there exist four major channels that handle the coolant flow. These are the fuel elements (including 19- and 12-hole fuel elements with holes of 0.00279-meter diameter), which handle most of the flow; the once-through tie rods, which contain the zinc hydride moderator sleeves; the M1 elements, which are unloaded peripheral elements; and the slat, which consists of several tubes at the boundary of the core. Both the 19- and the 12-hole fuel elements have most 


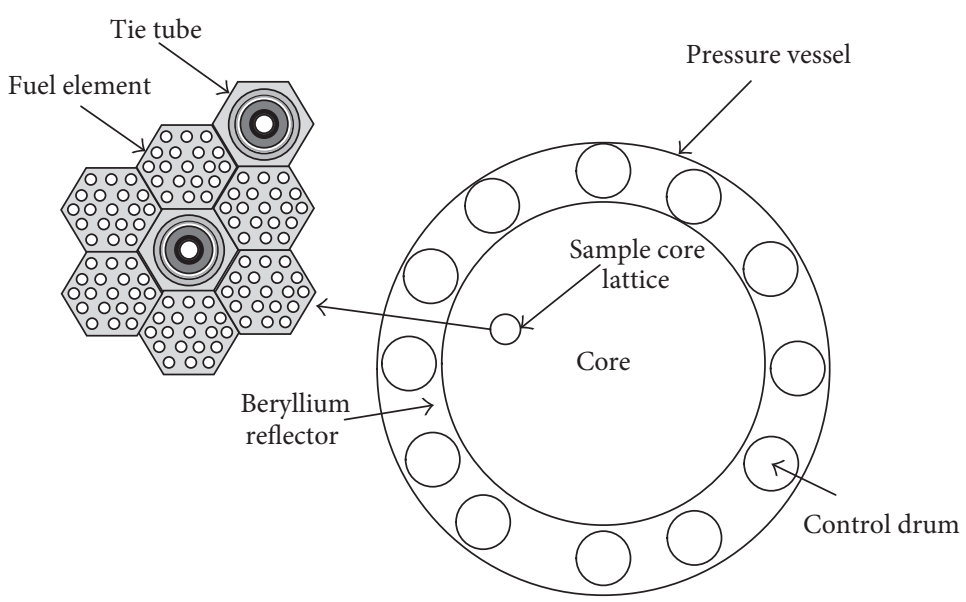

FIgURE 2: Top view of the core of a typical NERVA engine [11].

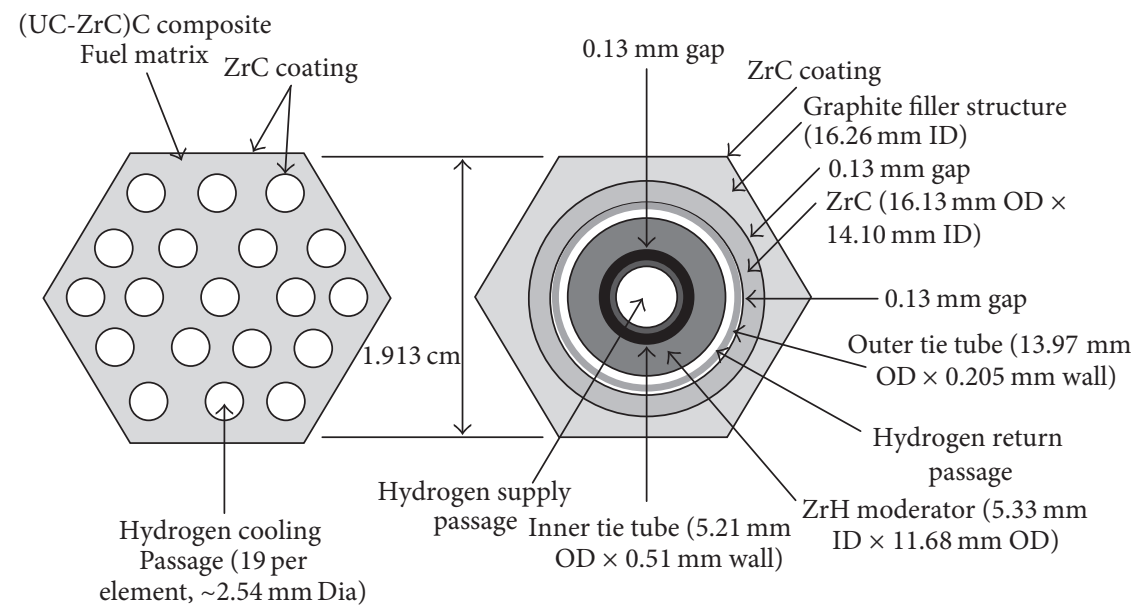

(a) Typical NERVA derived fuel element

(b) Typical NERVA derived tie tube

FIGURE 3: 19-hole fuel element and tie rod tube design of a typical NERVA engine [11].

coolant channels coated with $\mathrm{NbC}$ and a few coated with ZrC. The majority of channels had an additional coating of molybdenum. The 120 tie rod tubes in the core receive coolant directly from the 3 tie rod manifolds. Figure 3 presents a top view of a 19-hole fuel element along with a top view of a tie rod tube. With the tie rod tube on the right, the hydrogen coolant flows through both the inner and the outer tube. There is a bypass to the core known as the annulus. The annulus surrounds the slats. Between the slats and the uncooled filler elements is the invar wrapper with pyrographite strips on the outside. These are used for heat insulation. The annulus is surrounded by the beryllium reflector. The M1 elements have the same hexagonal shape as the 19-hole fuel elements and are neighbors to both types of fuel elements.

2.6. Nozzle of Pewee I. The coolant is a mixture of the coolants of annulus, slats, M1 elements, tie rods, and fuel element at the channel exits. The total flow rate adds up to $18.59 \mathrm{Kg} / \mathrm{s}$. The resultant coolant temperature as a result of the coolant mixing is then $1755.23 \mathrm{~K}$. The coolant flows through the nozzle and then is released into the atmosphere producing a thrust. The coolant pressure of $3.26 \mathrm{MPa}$ at the nozzle exit (Figure 1) is not provided in the original report by Finseth [13]. This pressure was calculated using pressure drop relations, which will be presented in Section 4.

2.7. Tests Done on Pewee I. Examples of experiments done on Pewee I are as follows: (i) short duration near full power and (ii) endurance at full power [13]. For part (i), the objectives here were (a) to establish the notion that the reactor control/safety systems do not encounter interference from the operation of all test and auxiliary systems, (b) to operate the reactor at approximately maximum power for a brief interval, (c) to undertake a series of experiments for mapping the moderator, and (d) to study control dynamics of the reactor. For part (ii), the objectives here were (a) to study the flow oscillations resulting from a brief interval of operation, (b) to establish the notion that the reactor can serve as a fuel element test bed, and (c) to run three 20-minute maximum 
power holds, with these holds surrounded by low power/low temperature cycles.

The results of the short duration run demonstrated the following: (a) reactor operating at power of $472 \mathrm{MW}$, (b) mean fuel exit temperature of $2450 \mathrm{~K}$, and (c) flow rate of approximately $18.1 \mathrm{~kg} / \mathrm{s}$. These results are approximate to the projected values [13].

In addition, the Pewee reactor operated at power greater than $508 \mathrm{MW}$, establishing the notion that the core can serve as a fuel test bed [13]. Pewee achieved a peak equivalent ideal vacuum specific impulse of 901 seconds. The specific impulse is defined as the total impulse divided by the weight of the propellant. A higher specific impulse is desired because this leads to a higher rocket equivalent exhaust velocity. In general, nuclear thermal rockets have greater specific impulses than chemical rockets and are hence preferred.

In addition, the Pewee experiments demonstrated that the fuel elements performed to the degree required. On the contrary, there were some issues of corrosion. Presented here are some examples of corrosion noticed on the Pewee fuel elements [15]:

(a) At least 8 to $53 \mathrm{~g}$ of fuel element mass was lost (resulting in a $20 \mathrm{~g}$ average).

(b) A mass loss per unit length (MULE) of 10 to 20 inches was noticed on the fuel elements.

(c) Core peripheral fuel elements underwent severe corrosion from the outside.

(d) Out of the 402 fuel elements, 46 were rigorously corroded or fissured.

Figures 4 and 5 illustrate the extent of the corrosion on the fuel elements.

\section{Background on Radiation Heat Transfer}

As mentioned in the Introduction, the purpose of this work is to investigate the radiation heat transfer in the Pewee core, resulting from a LOFA. Consider an opaque, gray, and diffuse surface (indexed using " $i$ ") that receives radiation from a fuel element surface (indexed using “ $j$ "); then, the radiosity of the $i$ th surface is given by

$$
J_{i}=\varepsilon_{i} \sigma T_{i}^{4}+\left(1-\varepsilon_{i}\right) \sum_{j=1}^{N} V_{i j} J_{j},
$$

where $\varepsilon_{i}$ is the emissivity of the $i$ th surface, $\sigma$ is the StefanBoltzmann constant, $T_{i}$ is the temperature of the $i$ th surface, $V_{i j}$ is the view factor from the $i$ th surface to the $j$ th surface, $J_{j}$ is the radiosity of the $j$ th surface, and $N$ is the number of the $j$ th surfaces. The view factor accounts for the orientation between the $i$ th surface and the $j$ th surface and is important in considering the radiation heat transfer. The view factor assumes that the radiation striking the $j$ th surface is directly proportional to the angle that the $j$ th surface subtends as seen from the $i$ th surface. Here, it is assumed that the $i$ th surface radiates uniformly in all directions to the $j$ th surface and the medium between them does not absorb, emit, or scatter radiation.

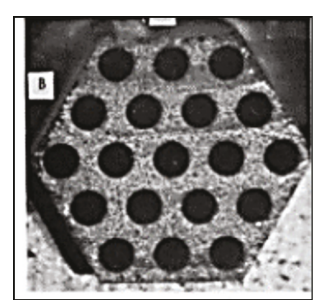

(a) $10-1 / 2$ inches, $0.35 \mathrm{~g} / \mathrm{inch}$

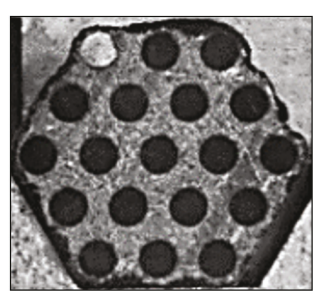

(c) 13 inches, $1.8 \mathrm{~g} / \mathrm{inch}$

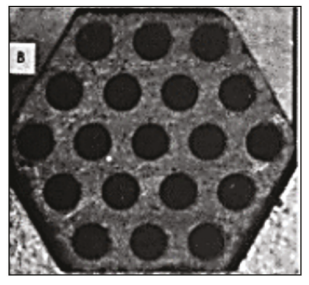

(a) $9-1 / 2$ inches, $0.25 \mathrm{~g} /$ inch

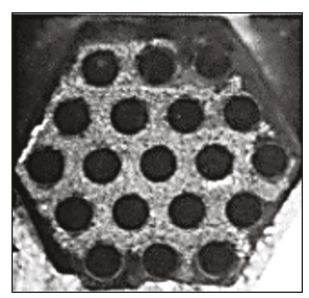

(c) 12 inches, $1.00 \mathrm{~g} / \mathrm{inch}$

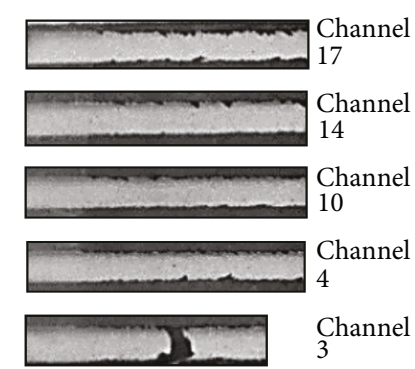

Coolant channels at 30-32 inches

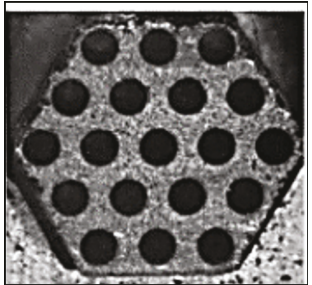

(b) $12-1 / 2$ inches, $1.0 \mathrm{~g} / \mathrm{inch}$

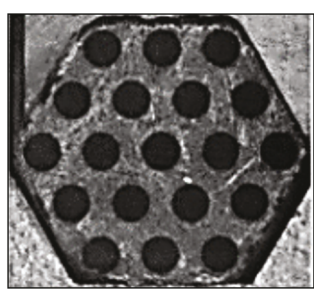

(d) 15 inches, $0.9 \mathrm{~g} /$ inch

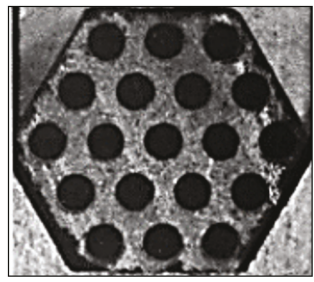

(b) 10 inches, $0.35 \mathrm{~g} /$ inch

(d) 13 inches, $1.4 \mathrm{~g} /$ inch

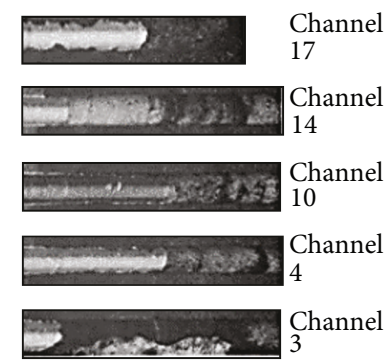

Coolant channels at 50-52 inches

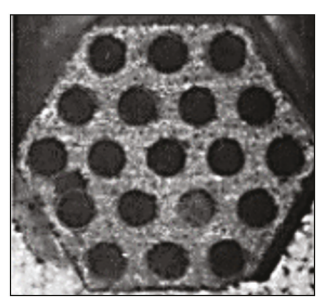

Figure 4: Fuel element corrosion along the axial length of channels and faces [12].

The resulting heat transfer per area is given by

$$
q=\frac{\varepsilon_{i}}{1-\varepsilon_{i}}\left(q_{\mathrm{BB}, i}-J_{i}\right),
$$

where

$$
q_{\mathrm{BB}, i}=\sigma T_{i}^{4}
$$

is the blackbody emissive power. 

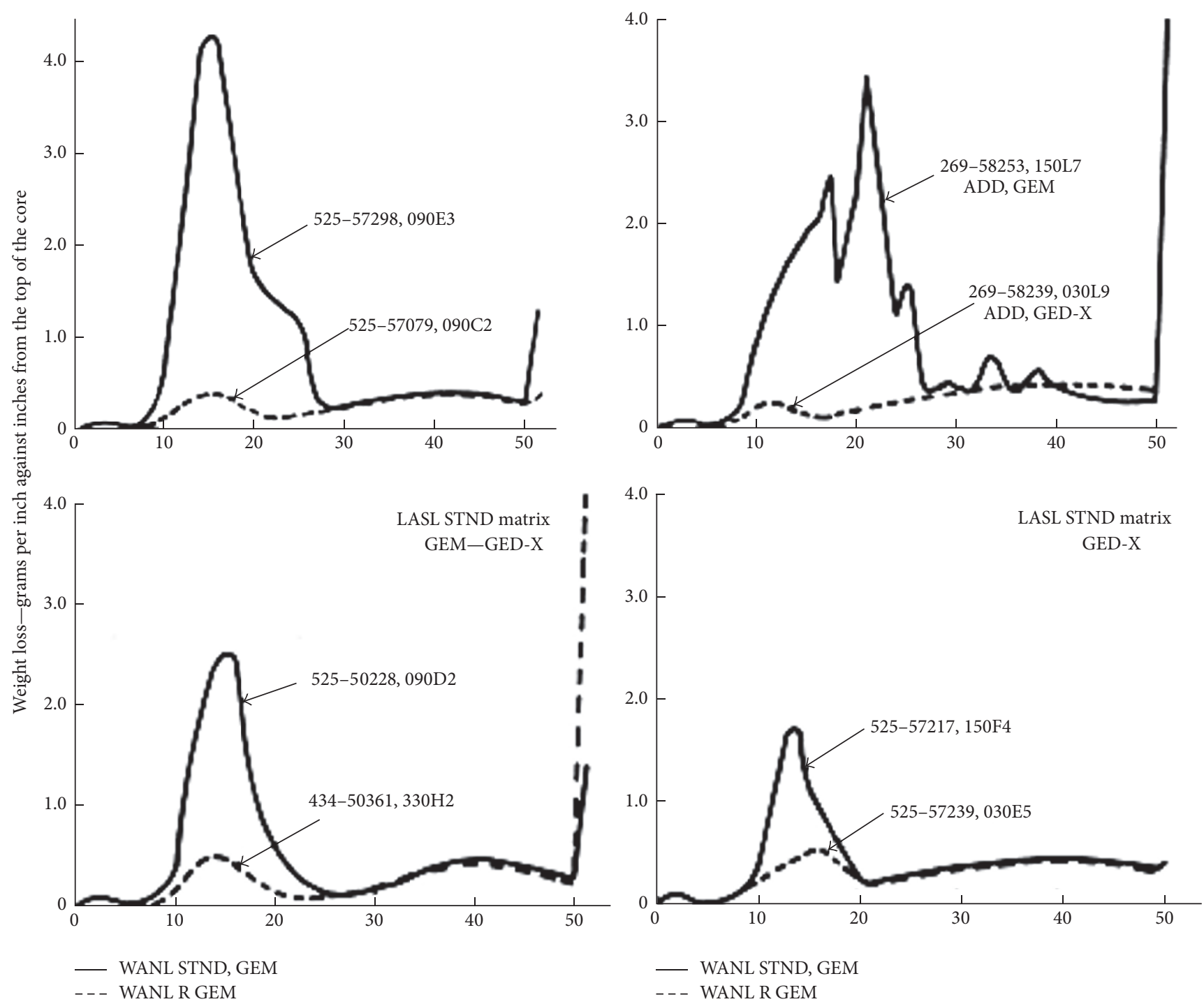

Figure 5: Incremental mass losses of some WANL and LASL Pewee fuel elements [12]. WANL: fabricated by Westinghouse Astronuclear Laboratory; LASL: fabricated by Los Alamos Scientific Laboratory; GED-X: G end, diffusion coating of cores and OD surfaces with NbC followed by bore overcoating with molybdenum; GED: G end, low temperature, methane assisted coated of bores and OD surfaces with NbC; STND: normal four, Thermax, and Varcum matrix; R: standard matrix impregnated with niobium resinate; ADD: standard matrix with 2.5 volume percent $\mathrm{NbC}$ powder additive. Numbers on the various corrosion curves are the serial numbers for the elements in specific locations.

Emissivity is a material's physical property that defines its ability to release heat through radiation. It is determined by the interaction of the electromagnetic field with the material. The material's dielectric constant or refraction index is used to conveniently capture this interaction. Emissivity not only depends on the materials' properties, but also on the radiation wavelength $\lambda$ and direction with respect to the surface normal. In transparent materials, normal emissivity can be described by

$$
\varepsilon_{n}(\lambda)=\frac{4 n}{(n+1)^{2}}, \quad\left(n=\frac{n_{2}}{n_{1}}\right)
$$

where $n_{1}$ and $n_{2}$ are refractive indices for oxide and air, which are functions of wavelength. From this relation, the emissivity is close to zero when optical refractive indices of both materials are equal to each other. In metals, normal emissivity can be approximated by the Hagen-Rubens relation given by

$$
\varepsilon_{n}(\lambda)=36.5\left(\frac{\rho_{e}}{\lambda}\right)^{1 / 2}-464 \frac{\rho_{e}}{\lambda}
$$

where $\rho_{e}$ is electrical resistivity in ohm-cm and $\lambda$ is the wavelength in $\mu \mathrm{m}$. In the case where the oxide layer is present on the surface of the metal, the emissivity is a combined contribution of the transparent layer and metal, which includes thickness of the oxide layer. Emissivity also depends on surface roughness and impurities. Pure polished material has the lowest emissivity, surface roughness results in higher emissivity, while the oxide layer increases emissivity further, eventually reaching the largest value when it has a sufficiently 
TABLE 2: Emissivity coefficients of $\mathrm{NbC}$ and $\mathrm{ZrC}$.

\begin{tabular}{lcc}
\hline & NbC & ZrC \\
\hline Temperature range (K) & $1700-2200$ & $1700-2200$ \\
Polished surface & 0.79 & 0.9 \\
Rough surface & 0.79 & 0.9 \\
Thermal treatment & 0.72 & 0.9 \\
Hydrogen exposure & 0.71 & 0.9 \\
\hline
\end{tabular}

TABLE 3: Emissivity coefficients of fresh and corroded materials.

\begin{tabular}{lc}
\hline Material & Emissivity \\
\hline Fresh NbC & 0.79 \\
Hydrogen exposed NbC & 0.71 \\
Uncorroded graphite & 0.49 \\
Corroded graphite & 0.76 \\
\hline
\end{tabular}

thick oxide layer. Sophisticated models of emissivity exist and incorporate a layered structure of oxide and morphology.

Corrosion increases the emissivity of the material. In general, corroded surfaces have higher emissivity coefficients than fresh surfaces. Heath and Aydogan [15] have identified some emissivity coefficients of the niobium carbide $(\mathrm{NbC})$ and zirconium carbide $(\mathrm{ZrC})$ coolant channels within the Pewee fuel elements. These emissivity coefficients are valid for temperatures greater than $1700 \mathrm{~K}$. Table 2 presents some examples of emissivity coefficients.

According to Heath and Aydogan [15], a typical Pewee coolant channel has $40 \% \mathrm{NbC}$ (or $\mathrm{ZrC}$ ) and $60 \%$ graphite. Out of the $40 \%$ of $\mathrm{NbC}$, some may be fresh and some may be corroded. The graphite part of the coolant channel will also have proportions of fresh and corroded emissivity coefficients. Table 3 presents the emissivity coefficients of the $\mathrm{NbC}$ and graphite portions.

Heath and Aydogan [15] came up with several emissivity coefficients of $\mathrm{NbC}$ and $\mathrm{ZrC}$ based channels with various fractions of fresh and corroded materials. Table 3 presents these emissivity coefficients. The subscripts $\mathrm{c}, \mathrm{cc}, \mathrm{g}$, and cg correspond to surfaces for coating, corroded coating (thermally and hydrogen exposed), graphite, and corroded graphite, respectively. The overall emissivity coefficient in each case was calculated using the relation

$$
\varepsilon=\Lambda_{A_{\mathrm{c}}} \varepsilon_{A_{\mathrm{c}}}+\Lambda_{A_{\mathrm{cc}}} \varepsilon_{A_{\mathrm{cc}}}+\Lambda_{A_{\mathrm{g}}} \varepsilon_{A_{\mathrm{g}}}+\Lambda_{A_{\mathrm{cg}}} \varepsilon_{A_{\mathrm{cg}}},
$$

where $\Lambda$ 's are coolant exposure ratios. More specifically, these are ratios of a specific material's graphite/coating area that is exposed to hydrogen coolant to the total area of all materials exposed to hydrogen coolant.

Figure 6 shows two surfaces ( 1 and 2), separated by a distance $r$ and each with surface areas of $S_{1}$ and $S_{2}$, respectively. The lines $n_{1}$ and $n_{2}$, which are normal to surfaces 1 and 2 , form angles $\vartheta_{1}$ and $\vartheta_{2}$ with the line that connects the two surfaces. The view factor from $S_{1}$ to $S_{2}$ is

$$
V_{1 \rightarrow 2}=\frac{1}{S_{1}} \int_{S_{1}} \int_{S_{2}} \frac{\cos \vartheta_{1} \cos \vartheta_{2}}{\pi r^{2}} d S_{2} d S_{1}
$$

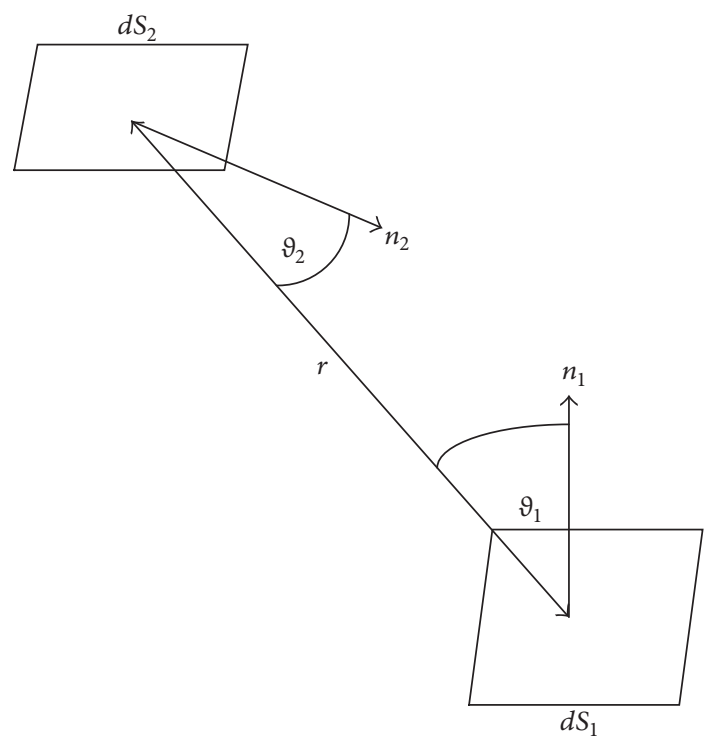

FIGURE 6: Diagram of surfaces in radiation heat transfer.

Similarly, the view factor from $S_{2}$ to $S_{1}$ is

$$
V_{2 \rightarrow 1}=\frac{1}{S_{2}} \int_{S_{2}} \int_{S_{1}} \frac{\cos \vartheta_{1} \cos \vartheta_{2}}{\pi r^{2}} d S_{1} d S_{2} .
$$

The radiation heat transfer between surfaces 1 and 2 is given by

$$
\begin{aligned}
\dot{Q} & =\varepsilon_{1} \sigma S_{1} V_{1 \rightarrow 2}\left(T_{1}^{4}-T_{2}^{4}\right) \\
& =-\varepsilon_{2} \sigma S_{2} V_{2 \rightarrow 1}\left(T_{2}^{4}-T_{1}^{4}\right),
\end{aligned}
$$

where $\dot{Q}$ is the heat transfer rate from the surface to the surroundings, $\varepsilon_{1}$ is the emissivity coefficient of surface $1, \varepsilon_{2}$ is the emissivity coefficient of surface 2, $\sigma$ is the Stefan-Boltzmann constant $\left(5.67 \times 10^{-8} \mathrm{~W} / \mathrm{m}^{2} \mathrm{~K}^{4}\right), T_{1}$ is the temperature of surface 1 , and $T_{2}$ is the temperature of surface 2 .

\section{System Modeling of Pewee I}

In order to model the LOFA on Pewee I, we need to create a Reactor Excursion Leak Analysis Program (RELAP) model of the rocket. In particular, RELAP is a special thermal hydraulics computer code developed by the Idaho National Laboratory in 1997. Since then, it has been used to model terrestrial nuclear power plants. Here, we give a brief description of the RELAP5 model of Pewee I. The Pewee nodalization diagram is presented in three parts in Figures 7-9. As per tradition with most RELAP5 nodalization diagrams, components are represented as pipes and volumes (including single volumes and time-dependent volumes) and have a unique 3digit number for identification. In this particular example, time-dependent volumes serve as boundary conditions for the propellant inlet, nozzle bolt cooling, pressure vessel bolt cooling, and tie rod manifold. The time-dependent junctions (TDJs) connect the time-dependent volumes to the main circuit. The major components are numbered and labeled 


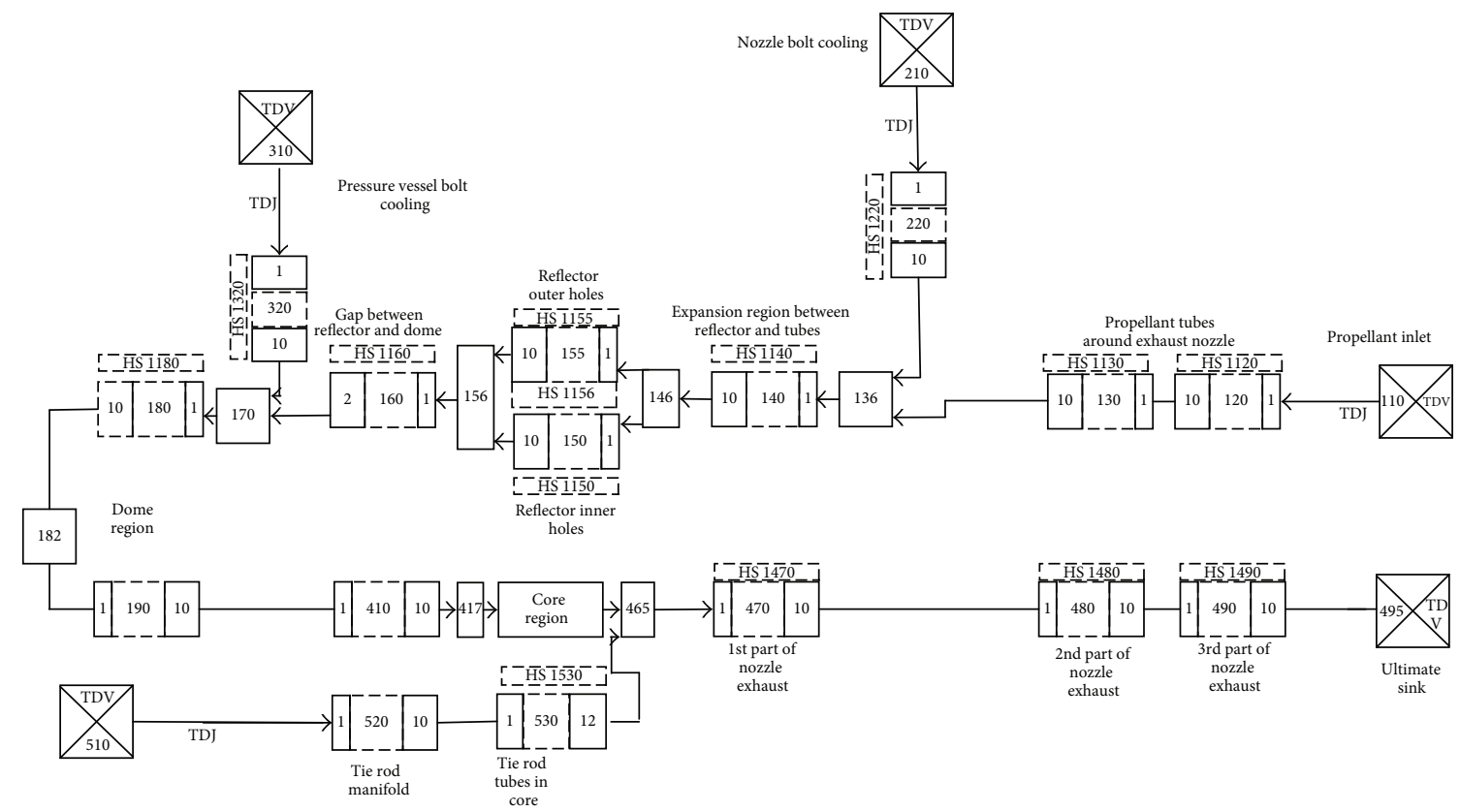

FIgURE 7: Overall RELAP5 nodalization diagram of Pewee I.
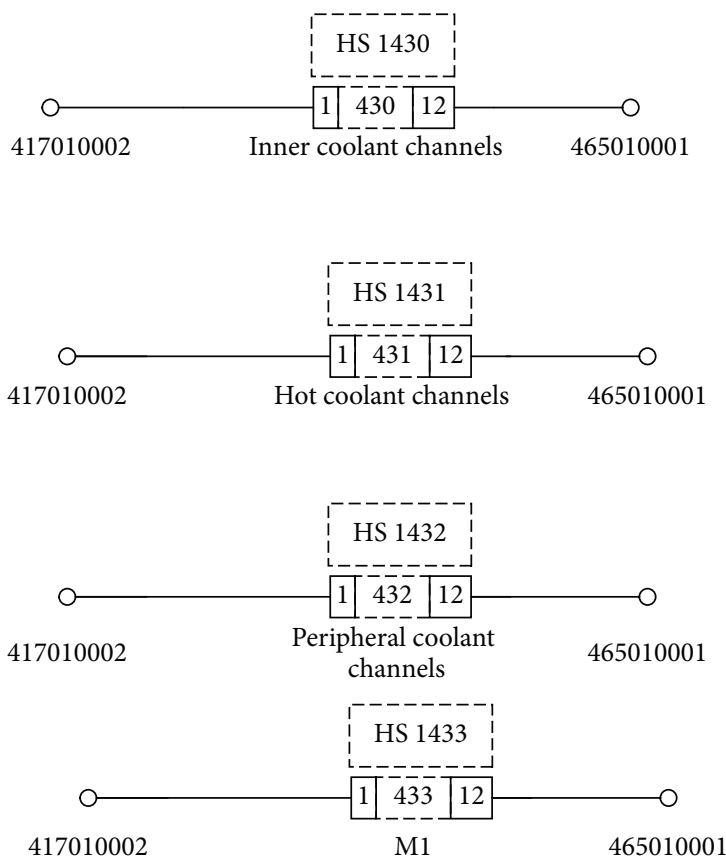
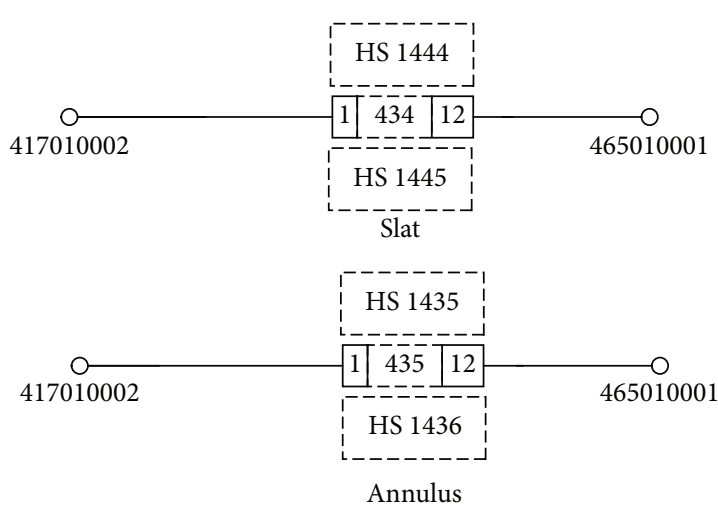

FIGURE 8: Pewee I detailed nodalization diagram of core components.

in Figures 7 and 8. Figure 8 presents each of the different core channels shown in Figure 1 such as the fuel elements, slat, annulus, tie rod tubes, and M1. The coolant channels within the fuel elements were divided into 3 main RELAP5 pipes: hydrodynamic (HV) 430 for inner coolant channels (ICC), HV 432 for peripheral coolant channels (PCC), and HV 431 for the hot coolant channels (HCC) of the hot fuel element. Due to the fact that fuel elements are scattered in a lattice such that they neighbor the tie rods and M1 elements, it was justified to model the fuel elements as separate pipes with their own heat structures. As is common with light water reactors in RELAP5, it is not unusual to model a hot fuel element, a cold fuel element, and average temperature fuel elements. The hot and cold fuel elements are needed for the extreme situations. Since Pewee is a hydrogencooled design, a hot fuel element is modeled for our extreme situations. The fuel elements have a total of 7554 coolant channels and so pipe component 430 represents the 7175 ICC holes, pipe component 431 represents 19 HCC holes, and pipe component 432 represents the remaining 360 PCC 


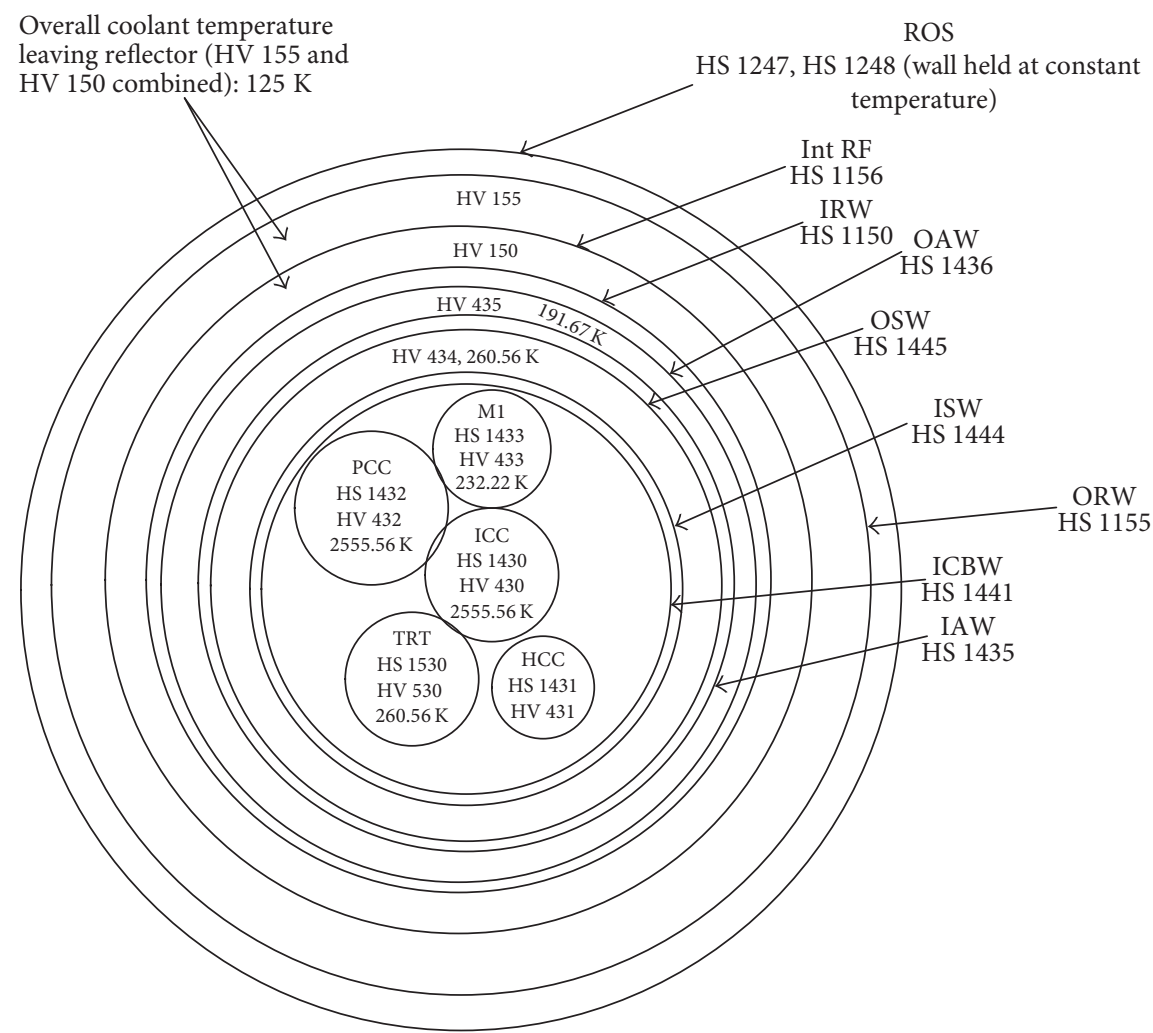

FIGURE 9: Pewee I radial nodalization diagram of core/reflector region. HS: heat structure; HV: hydrodynamic volume; M1: M1 elements; ICC: inner coolant channels; PCC: peripheral coolant channels; HCC: hot coolant channels; TRT: tie rod tubes; ICBW: inner core boundary wall; ISW: inner slat wall; OSW: outer slat wall; IAW: inner annulus wall; OAW: outer annulus wall; IRW: inner reflector wall; Int RW: intermediate reflector wall; ORW: outer reflector wall; ROS: rocket outer shell.

holes. There are heat structures attached to the core channels and reflector and they serve the purpose of modeling heat generation in the fuel elements and they transfer the heat to the neighboring structures. Since not all components can be represented on a single RELAP5 diagram, connections to the other parts of the circuit not visible in Figure 7 are indicated with component name, volume number, and face number in the form CCCVV000F (CCC for hydrodynamic volume (HV) number, VV for volume number, and $\mathrm{F}$ for face number ranging from 1 to 6 ) besides each circular node. For example, HV 430 is divided into 12 volumes and is connected to HV 417 at the front and HV 465 at the rear. The pipe obtains input from 417010002 (HV 417, volume 1, face 2) and transfers its output to 465010001 (HV 465, volume 1, face 1). In this work, face 1 of a pipe/single volume/time-dependent volume was designated as the inlet and face 2 was designated as the outlet.

Table 5 presents the pressures and temperatures set for the TDVs. These are our boundary conditions and are set either slightly higher or less than the required pressures. Table 6 presents the mass flows of the TDJs connected to the various TDVs. Table 7 presents the components in the RELAP diagrams (see Figures 7-9) with their average flow areas, lengths, and volumes.

Figures 7-9 show several heat structures (HS). In particular, HS 1430, 1431, and 1432 are generating heat and HS
$1433,1530,1435,1441,1155,1444,1445,1436,1150$, and 1156 are removing heat. Heat sinks HS 1247 and 1248 are on the outer shell of the rocket. Adding a heat structure to a hydrodynamic volume basically adds a wall of certain thickness and material to it. The outside environments/surroundings of HS 1247 and 1248 are held at space temperatures of $3 \mathrm{~K}$. Note that heat is transferred radially, as the center of the core is the hottest and the temperature at the rocket shell is the coldest. Heat structures 1470, 1480, and 1490 handle the heat transfer from the nozzle exit to the expansion region and coolant tubes, respectively. For example, HS 1470 serves as a link between HV 140 and HV 470, HS 1480 serves as a link between HV 130 and HV 480, and HS 1490 serves as a link between HV 120 and HV 490.

RELAP5 heat structures require that material properties such as volumetric heat capacities and thermal heat conductivities be presented. By default, RELAP5 has the property tables for the following materials: gap, carbon steel, stainless steel, uranium dioxide, and Zircaloy. In our case, the volumetric heat capacities and thermal conductivities were used for uranium carbide, Zircaloy, graphite, beryllium, aluminum, stainless steel, and invar. Wherever deemed necessary, the properties were extrapolated to cover a temperature range of $0 \mathrm{~K}$ to $5000 \mathrm{~K}$.

In order to get the correct temperatures in the core and reflector region, we have applied the conduction model that 
comes with RELAP5. RELAP5 requires that two surfaces (represented by heat structures) in conduction follow the trivial relationship

$$
C_{1} S_{1} F_{1 \rightarrow 2}=C_{2} S_{2} F_{2 \rightarrow 1},
$$

where $C$ 's represent conductances, $S$ 's represent surface areas, and $F$ 's represent area factors, and subscripts 1 and 2 denote surfaces 1 and 2. RELAP5 automatically calculates the surface area of each heat structure. The values of $C$ 's and $F$ 's need to be adjusted in order to get the desired temperatures. As for tuning the temperatures in the nozzle inlet and propellant inlet sections, the fouling factors of the heat structures were adjusted.

Figure 1 has most of the information required to do the pressure tuning. The only information missing from Figure 1 is the pressure leaving the nozzle exit and into the atmosphere. For this case, we ended up estimating the pressure drop through the nozzle using the following pressure drop relation [16]:

$$
\Delta P_{\text {total }}=\Delta P_{\text {form }}+\Delta P_{\text {acc }}+\Delta P_{\text {fric }},
$$

where $\Delta P_{\text {form }}$ represents the losses due to form and is given by

$$
\Delta P_{\text {form }}=K_{c} \rho \frac{u_{2}^{2}}{2},
$$

$\Delta P_{\text {acc }}$ represents the losses due to acceleration and is given by

$$
\Delta P_{\mathrm{acc}}=\rho \frac{u_{2}^{2}-u_{1}^{2}}{2},
$$

and $\Delta P_{\text {fric }}$ represents the losses due to friction and is given by

$$
\Delta P_{\text {fric }}=\frac{f \rho u^{2} L}{2 D_{h}} .
$$

Upon using these relations, a pressure drop of $1.025 \mathrm{MPa}$ was calculated. This means the pressure leaving the nozzle exit and entering the atmosphere is $3.257 \mathrm{MPa}$. The pressure drops throughout the rocket were tuned by adjusting the roughness coefficients and the forward and reverse Reynolds loss coefficients. The hydraulic diameter of all pipes was calculated and was required in order to help tune the pressures.

As discussed earlier in Section 4, the temperature in the Pewee core was tuned by invoking the conduction models. The same input deck was taken and a radiation heat transfer model was incorporated. A fresh emissivity coefficient for the fuel element coolant channels was defined. It was assumed that the weight fraction of the $\mathrm{NbC}$ is $40 \%$ and the weight fraction of the graphite is $60 \%$. Using the fresh and uncorroded emissivity coefficients defined in Table 3 and utilizing (6), the fresh emissivity of the coolant channel is given by

$$
\varepsilon=(0.4) 0.79+(0.6) 0.49=0.61 \text {. }
$$

Similar to (10), the radiation heat transfer model in RELAP5 requires that

$$
\varepsilon_{1} S_{1} V_{1 \rightarrow 2}=\varepsilon_{2} S_{2} V_{2 \rightarrow 1} .
$$

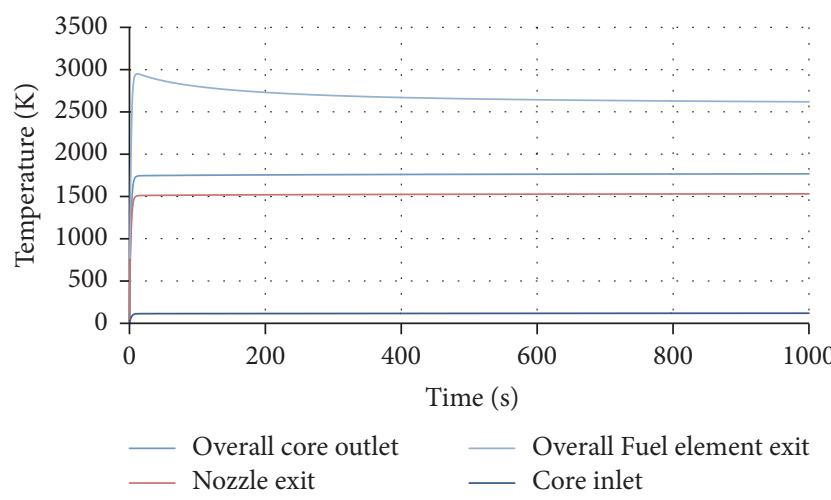

Figure 10: Temperatures in the Pewee steady-state model.

RELAP5 also requires that the view factors associated with each surface sum up to 1.0. Using the fresh emissivity of 0.61 , the view factors in the RELAP5 model were calculated and adjusted such that they resemble the parameters in Figure 1 as best as possible. Since the participating medium here is hydrogen, it should not emit, absorb, or scatter radiation. If the participating medium had asymmetric molecules, such as, $\mathrm{H}_{2} \mathrm{O}, \mathrm{CO}_{2}, \mathrm{CO}, \mathrm{SO}_{2}$, and hydrocarbons, then it will participate in the radiation process via absorption.

The RELAP5 model of the Pewee design has been validated in steady-state mode. Table 8 presents some sample tuned parameters and Figure 10 presents a plot of the temperatures reaching steady state within 1000 seconds.

\section{System Response of Pewee due to Loss-of-Flow Accidents}

The transient runs were initiated on the completed steadystate runs. Transient runs in RELAP5 require a RESTART problem to be resumed from the end time of the steady-state run. At a time of 501 seconds from the start of the RESTART problem, the mass flow rate going through the system was decreased. The simulation was run for a total of 3501 seconds. Table 9 presents a summary of the events in each transient run. Table 10 presents a summary of the transient cases.

Emissivity coefficients of 0.66 and 0.75 have corrosion (see Table 4). Basically, Case 1(a), Case 2(a), and Case 3(a) are cases that have a complete LOFA and Case 1(d), Case 2(d), and Case 3(d) are cases with no LOFA. Cases (b) and (c) are those with partial LOFAs.

Figure 11 presents the mass flow rates resulting from the LOFAs. Figure 12 presents the average pressure in the core for Cases 1(a)-1(d). From Figure 11, the rapid change in mass flow rate can be seen. Figure 12 appears to show a similar shape to that of Figure 11. Table 11 presents the average pressure in the core for all these cases. From Table 11, Case (a)s have similar pressures, Case (b)s have similar pressures, Case (c)s have similar pressures, and Case (d)s have similar pressures.

Figure 13 presents the temperature of the fuel elements. Figure 14 presents the material temperature of PCC. In both Figures 13 and 14, the melting point of UC, which is $2768.15 \mathrm{~K}$, is included in the plots [17]. Please note in Figure 13 that 
TABLE 4: Area weighted emissivity with various stages of corrosion.

\begin{tabular}{lccccc}
\hline$\Lambda_{A_{\mathrm{c}}}$ & $\Lambda_{A_{\mathrm{cc}}}$ & $\Lambda_{A_{\mathrm{g}}}$ & $\Lambda_{A_{\mathrm{cg}}}$ & $\varepsilon \mathrm{NbC}$ & $\varepsilon \mathrm{ZrC}$ \\
\hline 0.06 & 0.04 & 0.52 & 0.38 & 0.62 & 0.63 \\
0.17 & 0.03 & 0.25 & 0.55 & 0.7 & 0.72 \\
0.08 & 0.3 & 0.33 & 0.29 & 0.66 & 0.72 \\
0.43 & 0.08 & 0.39 & 0.1 & 0.66 & 0.73 \\
0.38 & 0.1 & 0.36 & 0.16 & 0.67 & 0.73 \\
0.41 & 0.03 & 0.33 & 0.23 & 0.68 & 0.73 \\
0.04 & 0.48 & 0.26 & 0.22 & 0.66 & 0.76 \\
0.05 & 0.51 & 0.28 & 0.16 & 0.66 & 0.76 \\
0.5 & 0.01 & 0.2 & 0.29 & 0.72 & 0.78 \\
0.25 & 0.34 & 0.21 & 0.2 & 0.69 & 0.79 \\
0.19 & 0.24 & 0.09 & 0.48 & 0.73 & 0.8 \\
0.05 & 0.56 & 0.19 & 0.19 & 0.68 & 0.79 \\
0.41 & 0.17 & 0.14 & 0.28 & 0.73 & 0.8 \\
0.54 & 0.1 & 0.17 & 0.19 & 0.73 & 0.8 \\
0.05 & 0.68 & 0.23 & 0.04 & 0.67 & 0.8 \\
0.45 & 0.35 & 0.16 & 0.04 & 0.71 & 0.83 \\
0.18 & 0.39 & 0 & 0.43 & 0.75 & 0.84 \\
0.05 & 0.67 & 0.04 & 0.24 & 0.72 & 0.85 \\
0.37 & 0.45 & 0.03 & 0.15 & 0.74 & 0.87 \\
\hline
\end{tabular}

TABLE 5: Record of pressures and temperatures for time-dependent volumes.

\begin{tabular}{lcc}
\hline Name & Pressure $(\mathrm{MPa})$ & Temperature $(\mathrm{K})$ \\
\hline 110 & 7.0 & 28.78 \\
210 & 7.0 & 28.78 \\
310 & 7.0 & 28.78 \\
510 & 6.3 & 28.78 \\
495 & 3.15 & 28.78 \\
\hline
\end{tabular}

TABLE 6: Record of mass flows from TDVs.

\begin{tabular}{lc}
\hline Starting TDV & Mass flow rate through TDJ \\
\hline 110 & 13.25 \\
210 & 0.41 \\
310 & 0.41 \\
510 & 4.54 \\
\hline
\end{tabular}

many of the curves overlap with each other. In particular, all Case (a)s are clumped together, all Case (b)s are clumped together, all Case (c)s are clumped together, and all Case (d)s are clumped together. Table 12 presents the radiation heat transfer from the fuel elements to the cold surfaces. Generally, the radiation heat transfer rate increases as the flow rate through the reactor system is decreased. This sort of trend is noted in the results of Case (b)s, Case (c)s, and Case (d)s. However, the total radiation heat transfer drops when there is a complete LOFA as shown in the results of Case (a)s. This is due to the fuel elements heating up the cold surfaces and hence decreasing the $\left(T_{h}{ }^{4}-T_{c}{ }^{4}\right)$ difference.

Figure 14 very clearly shows the differences caused by the emissivity coefficients on the PCC material temperatures as
TABLE 7: Flow areas, lengths, and volumes of RELAP components.

\begin{tabular}{lccc}
\hline Component & $\begin{array}{c}\text { Average flow } \\
\text { area }\left(\mathrm{m}^{2}\right)\end{array}$ & Total length $(\mathrm{m})$ & Volume $\left(\mathrm{m}^{3}\right)$ \\
\hline 110 & $1.00 E+06$ & $1.00 E+00$ & $1.00 E+06$ \\
120 & $8.01 E-03$ & $4.44 E-01$ & $3.56 E-03$ \\
130 & $8.01 E-03$ & $3.77 E-01$ & $3.02 E-03$ \\
140 & $2.77 E-01$ & $4.20 E-01$ & $1.16 E-01$ \\
146 & $2.87 E-02$ & $1.00 E-02$ & $2.87 E-04$ \\
150 & $5.41 E-03$ & $1.27 E+00$ & $6.87 E-03$ \\
155 & $2.33 E-02$ & $1.27 E+00$ & $2.96 E-02$ \\
156 & $5.39 E-01$ & $1.00 E-02$ & $5.39 E-03$ \\
160 & $5.39 E-01$ & $5.08 E-02$ & $2.74 E-02$ \\
170 & $2.32 E-01$ & $1.00 E-02$ & $2.32 E-03$ \\
180 & $2.32 E-01$ & $2.66 E-01$ & $6.16 E-02$ \\
190 & $1.43 E-01$ & $2.66 E-01$ & $3.79 E-02$ \\
210 & $1.00 E+06$ & $1.00 E+00$ & $1.00 E+06$ \\
220 & $3.02 E-03$ & $2.19 E-01$ & $6.61 E-04$ \\
310 & $1.00 E+06$ & $1.00 E+00$ & $1.00 E+06$ \\
320 & $3.02 E-03$ & $2.19 E-01$ & $6.61 E-04$ \\
410 & $1.05 E-01$ & $5.08 E-02$ & $5.33 E-03$ \\
417 & $8.15 E-02$ & $1.00 E-02$ & $8.15 E-04$ \\
430 & $7.25 E-02$ & $1.32 E+00$ & $9.57 E-02$ \\
431 & $2.19 E-04$ & $1.32 E+00$ & $2.89 E-04$ \\
432 & $3.49 E-03$ & $1.32 E+00$ & $4.61 E-03$ \\
433 & $1.27 E-04$ & $1.32 E+00$ & $1.67 E-04$ \\
434 & $2.09 E-03$ & $1.32 E+00$ & $2.76 E-03$ \\
435 & $1.15 E-03$ & $1.32 E+00$ & $1.52 E-03$ \\
465 & $8.25 E-02$ & $1.00 E-02$ & $8.25 E-04$ \\
470 & $2.32 E-01$ & $4.20 E-01$ & $9.75 E-02$ \\
480 & $9.57 E-02$ & $2.73 E-01$ & $2.61 E-02$ \\
490 & $5.21 E-02$ & $4.01 E-01$ & $2.09 E-02$ \\
495 & $1.00 E+06$ & $1.00 E+00$ & $1.00 E+06$ \\
510 & $1.00 E+06$ & $1.00 E+00$ & $1.00 E+06$ \\
520 & $1.34 E+00$ & $9.49 E-03$ \\
530 & $1.32 E+00$ & $1.11 E-02$ \\
\hline & & &
\end{tabular}

compared to Figure 13. The top three curves in Figure 14 are those of Case 1(a), Case 2(a), and Case 3(a). Since Case 3(a) has the highest emissivity among the three, temperature here is lower. Case 1(a) has the lowest emissivity among the three and hence has the highest temperature.

From Table 13, the radiation heat transfer in the PCC increases with decreasing flow rate. Contrary to Table 12, the radiation heat transfer rate in Case (a)s is greater than that in Case (d)s. Comparing the radiation heat transfer between identical cases in Tables 12 and 13, we can see that the radiation heat transfers in all Case (a)s are almost identical to each other. This shows that when there is a complete LOFA, the PCC handles the majority of the radiation heat transfer.

From Figure 13, the fuel element temperature will exceed the melting point of UC, even if a partial LOFA causes 
TABLE 8: Sample tuned parameters.

\begin{tabular}{lccc}
\hline Component & $\begin{array}{c}\text { Mass flow rate }(\mathrm{kg} / \mathrm{s}) \\
\text { (designed value) }\end{array}$ & $\begin{array}{c}\text { Temperature }(\mathrm{K}) \\
\text { (designed value) }\end{array}$ & $\begin{array}{c}\text { Pressure }(\mathrm{MPa}) \\
(\text { designed value })\end{array}$ \\
\hline $\begin{array}{l}\text { Reflector exit } \\
\text { Core inlet }\end{array}$ & $13.65(13.65)^{1}$ & $126.27(125.00)$ & $5.58(5.71)$ \\
$\begin{array}{l}\text { Core exit (including ICC, HCC, PCC, M1, slat, annulus, and tie } \\
\text { rod) }\end{array}$ & $14.06(14.06)$ & $118.50(127.78)$ & $5.44(5.56)$ \\
Fuel element exit (including ICC, HCC, and PCC) & $18.60(18.59)$ & $1767.08(1755.23)$ & $4.19(4.28)$ \\
\hline
\end{tabular}

${ }^{1}$ The second entry in parenthesis is the design value for each case.

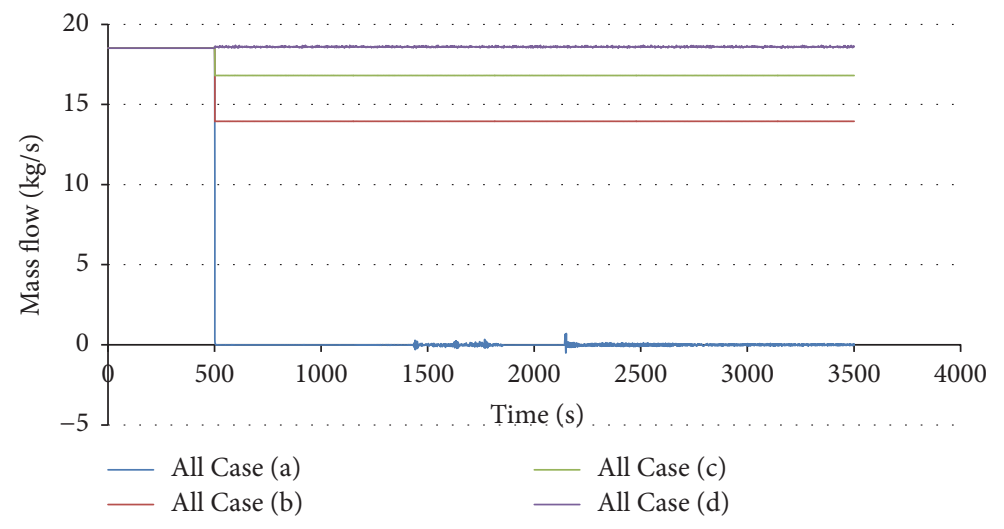

Figure 11: Mass flow rates resulting from the LOFAs.

TABLE 9: Events scheduled for the RESTART problem.

\begin{tabular}{lr}
\hline Time $(\mathrm{s})$ & Event \\
\hline 0 & RESTART problem resumes \\
501 & Flow rate throughout the system is decreased \\
3501 & RESTART problem ends \\
\hline
\end{tabular}

the total flow rate in the core to fall down to $75 \%$ of the original. Moreover, from Figure 13, the melting point of UC is also exceeded when the total flow rate falls down to $90 \%$ of the original. Eventually, the melting points of graphite, $\mathrm{NbC}$, and $\mathrm{ZrC}$ can also be reached. The melting points of graphite, $\mathrm{NbC}$, and $\mathrm{ZrC}$ are $3773.15 \mathrm{~K}$ [18], 3795.15 K [19], and $3303-3530 \mathrm{~K}$ [20], respectively. From Figures 13 and 14 , further severe accident analysis is needed to access the situation for temperatures beyond the melting point. The NASA Mars missions designated to occur during the 2030s necessitate an operation time of 2 hours when the NTR is operating at full power [21]. The longest engine burn time is 50 minutes [21]. NASA estimates that the approximate travel time between Earth and Mars is 100 days [22]. However, a 100day journey does not entail that the reactor has to function continuously for that same time frame. Instead, the reactor runs for 2 hours momentarily during the journey in order to give the rocket initial speed and let it coast naturally in space. Each time the rocket requires an increase in speed or change in direction, reactor operation will resume again. Assuming that Pewee I is operating at full power and deployed for the NASA Mars mission, the question would arise as to what action needs to be taken in order to counteract LOFA. If
TABLE 10: Summary of transient cases considered.

\begin{tabular}{|c|c|c|c|}
\hline Case ID & $\begin{array}{l}\text { FE channel } \\
\text { emissivity }\end{array}$ & $\begin{array}{c}\text { Flow rate }(\%) \\
\text { of original }\end{array}$ & Description of case \\
\hline 1(a) & 0.61 & 0 & $\begin{array}{l}\text { Fresh surface, complete } \\
\text { LOFA }\end{array}$ \\
\hline $1(\mathrm{~b})$ & 0.61 & 75 & $\begin{array}{l}\text { Fresh surface, 2nd partial } \\
\text { LOFA }\end{array}$ \\
\hline $1(\mathrm{c})$ & 0.61 & 90 & $\begin{array}{l}\text { Fresh surface, 1st partial } \\
\text { LOFA }\end{array}$ \\
\hline $1(\mathrm{~d})$ & 0.61 & 100 & Fresh surface, no LOFA \\
\hline $2(a)$ & 0.66 & 0 & $\begin{array}{l}\text { Corroded surface, } \\
\text { complete LOFA }\end{array}$ \\
\hline 2(b) & 0.66 & 75 & $\begin{array}{l}\text { Corroded surface, 2nd } \\
\text { partial LOFA }\end{array}$ \\
\hline $2(c)$ & 0.66 & 90 & $\begin{array}{l}\text { Corroded surface, 1st } \\
\text { partial LOFA }\end{array}$ \\
\hline $2(d)$ & 0.66 & 100 & $\begin{array}{l}\text { Corroded surface, no } \\
\text { LOFA }\end{array}$ \\
\hline $3(a)$ & 0.75 & 0 & $\begin{array}{l}\text { Very corroded surface, } \\
\text { complete LOFA }\end{array}$ \\
\hline $3(b)$ & 0.75 & 75 & $\begin{array}{l}\text { Very corroded surface, } \\
\text { 2nd partial LOFA }\end{array}$ \\
\hline $3(\mathrm{c})$ & 0.75 & 90 & $\begin{array}{l}\text { Very corroded surface, 1st } \\
\text { partial LOFA }\end{array}$ \\
\hline $3(d)$ & 0.75 & 100 & $\begin{array}{l}\text { Very corroded surface, no } \\
\text { LOFA }\end{array}$ \\
\hline
\end{tabular}

the LOFA occurred early during the burn time, scramming the reactor could be sufficient to prevent meltdown of the 


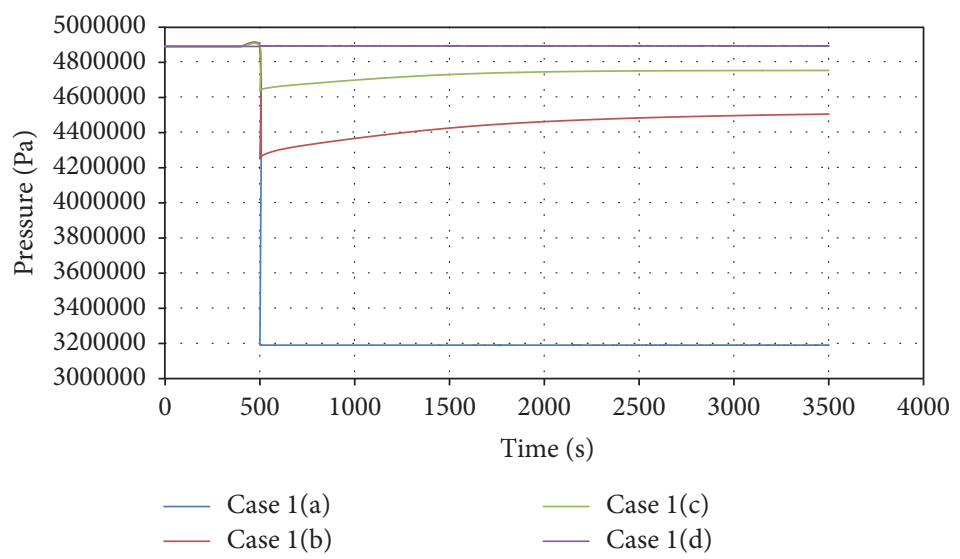

FIGURE 12: Average pressure in the core.

TABLE 11: Average pressure level in the core.

\begin{tabular}{lc}
\hline Case ID & Average pressure in the core $(\mathrm{Pa})$ \\
\hline $1(\mathrm{a})$ & 3190060 \\
$1(\mathrm{~b})$ & 4502540 \\
$1(\mathrm{c})$ & 4750665 \\
$1(\mathrm{~d})$ & 4890275 \\
$2(\mathrm{a})$ & 3190155 \\
$2(\mathrm{~b})$ & 4503350 \\
$2(\mathrm{c})$ & 4750360 \\
$2(\mathrm{~d})$ & 4889500 \\
$3(\mathrm{a})$ & 3190395 \\
$3(\mathrm{~b})$ & 4504370 \\
$3(\mathrm{c})$ & 4749755 \\
$3(\mathrm{~d})$ & 4888835 \\
\hline
\end{tabular}

TABLE 12: Radiation heat transfer rates from transient cases.

Radiation heat transfer rate Radiation heat transfer rate Case ID between fuel elements and as percentage of power cold surfaces $(W) \quad$ generated in fuel elements

\begin{tabular}{lll}
\hline $1(\mathrm{a})$ & $6.63 E+6$ & 1.44 \\
$1(\mathrm{~b})$ & $3.45 E+7$ & 7.47 \\
$1(\mathrm{c})$ & $2.06 E+7$ & 4.47 \\
$1(\mathrm{~d})$ & $1.51 E+7$ & 3.27 \\
$2(\mathrm{a})$ & $6.76 E+6$ & 1.46 \\
$2(\mathrm{~b})$ & $3.66 E+7$ & 7.92 \\
$2(\mathrm{c})$ & $2.19 E+7$ & 4.75 \\
$2(\mathrm{~d})$ & $1.60 E+7$ & 3.48 \\
$3(\mathrm{a})$ & $6.94 E+6$ & 1.50 \\
$3(\mathrm{~b})$ & $4.01 E+7$ & 8.68 \\
$3(\mathrm{c})$ & $2.42 E+7$ & 5.24 \\
$3(\mathrm{~d})$ & $1.77 E+7$ & 3.84 \\
\hline
\end{tabular}

core. If the LOFA happened later during the burn time, measures such as scramming the reactor and then passing an emergency system coolant could be needed to remove the decay heat. There remains the question as to whether this
TABLE 13: Radiation heat transfer rates from PCC to cold surfaces.

\begin{tabular}{lcc}
\hline Case ID & $\begin{array}{c}\text { Radiation heat transfer rate } \\
\text { between PCC and cold } \\
\text { surfaces }(W)\end{array}$ & $\begin{array}{c}\text { Radiation heat transfer rate } \\
\text { as percentage of power } \\
\text { generated in PCC }\end{array}$ \\
\hline $1(\mathrm{a})$ & $6.62 E+06$ & 28.49 \\
$1(\mathrm{~b})$ & $6.25 E+06$ & 26.90 \\
$1(\mathrm{c})$ & $4.51 E+06$ & 19.42 \\
$1(\mathrm{~d})$ & $3.66 E+06$ & 15.76 \\
$2(\mathrm{a})$ & $6.75 E+06$ & 29.03 \\
$2(\mathrm{~b})$ & $6.41 E+06$ & 27.55 \\
$2(\mathrm{c})$ & $4.65 E+06$ & 20.01 \\
$2(\mathrm{~d})$ & $3.79 E+06$ & 16.31 \\
$3(\mathrm{a})$ & $6.93 E+06$ & 29.82 \\
$3(\mathrm{~b})$ & $6.65 E+06$ & 28.60 \\
$3(\mathrm{c})$ & $4.90 E+06$ & 21.07 \\
$3(\mathrm{~d})$ & $4.00 E+06$ & 17.18 \\
\hline
\end{tabular}

emergency coolant will operate in an open cycle or closed loop or whether the heat removal process will be active or passive.

\section{Conclusions}

The LOFA in the Pewee rocket system has been modeled using RELAP5-3D. First, a steady-state model was developed to achieve steady-state conditions for the main thermalhydraulic parameters. Then, transients were done on the steady-state model such that partial and complete LOFAs were assumed. It was assumed that the flow rate dropped by $0 \%, 10 \%, 25 \%$, and $100 \%$. These were done on a reactor system that has fuel element channel surfaces with fresh and corroded surfaces. In particular, an emissivity of 0.75 represents a highly corroded surface, an emissivity of 0.66 represents a corroded surface, and an emissivity of 0.61 represents a fresh surface. In general, LOFA causes the average pressure level in the core to decrease (see Figure 12 and Table 11). As expected, a partial or complete LOFA causes the temperature of the fuel elements to become greater than 


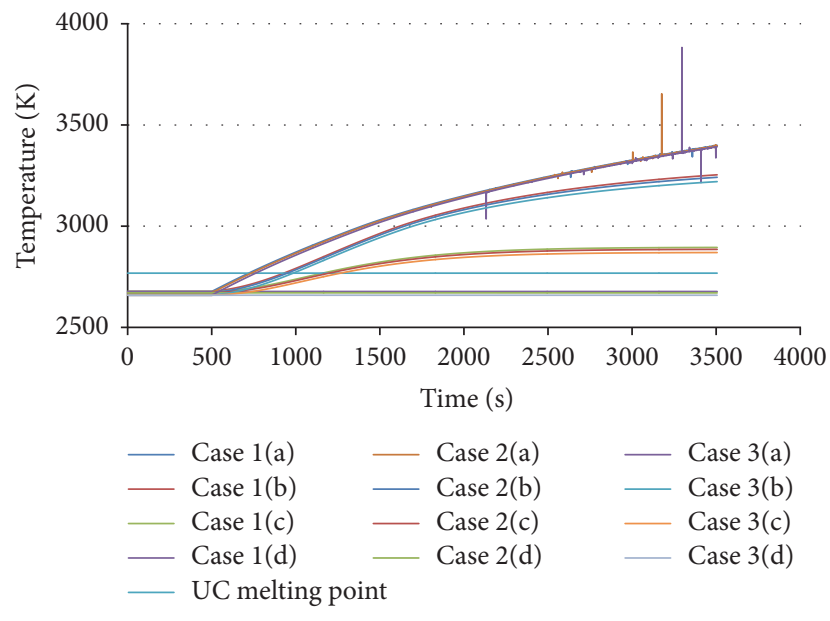

Figure 13: Temperature of fuel elements.

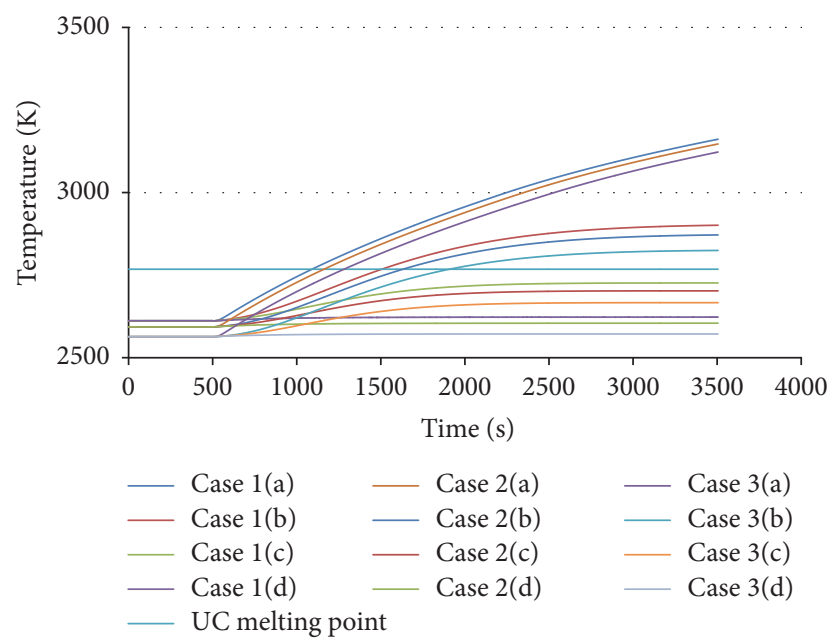

Figure 14: Material temperature of PCC.

normal (shown in Figures 13 and 14). Even for a reactor flow rate that has been reduced by $10 \%$, the temperature of the fuel elements exceeds the UC melting point (see Figure 13). In general, the radiation heat transfer between the fuel elements and cold surface increases as the flow through the reactor is decreased (see Tables 12 and 13). However, a complete LOFA causes the radiation heat transfer rate between the fuel elements and the cold surfaces to decrease (see Table 12). This is due to the fuel elements heating up the cold surfaces and hence decreasing the $\left(T_{h}{ }^{4}-T_{c}{ }^{4}\right)$ difference. In addition, the radiation heat transfer in the fuel elements during a complete LOFA is governed primarily by the radiation heat transfer between the PCC and the cold surfaces (see Tables 12 and 13). A safety system will be needed to counteract the decay heat resulting from scamming the reactor after LOFA. This safety system could operate in an open or closed loop and have a heat removal process that is active or passive.

\section{Nomenclature}

Abbreviations

HCC: Hot coolant channels

HS: $\quad$ RELAP heat structure

HV: RELAP hydrodynamic volume

ICC: Inner coolant channels

NASA: National Aeronautics and Space Administration

NbC: Niobium carbide

NERVA: Nuclear Engine for Rocket Vehicle Application

PCC: Peripheral coolant channels

NTR: Nuclear thermal rocket

$P: \quad$ Pressure $(\mathrm{Pa})$ in Figure 1

RELAP: Reactor Excursion Leak Analysis Program

Stdy-st: Steady-state problem type declaration in RELAP

T: $\quad$ Temperature (K) in Figure 1

TDJ: Time-dependent junction

TDV: Time-dependent volume

TREAT: Transient Reactor Test

$W: \quad$ Mass flow rate $(\mathrm{kg} / \mathrm{s})$ in Figure 1

WANL: Westinghouse Astronuclear Laboratory

ZrC: $\quad$ Zirconium carbide.

Symbols

$\dot{Q}: \quad$ Heat transfer from the surface to the surroundings

$\varepsilon: \quad$ Emissivity of surface

$\varepsilon_{A}: \quad$ Emissivity of graphite/NbC/ZrC surfaces

$\Lambda_{A}$ : Coolant exposure ratio of graphite/NbC/ZrC surface

$\sigma: \quad$ Stefan-Boltzmann constant

$S: \quad$ Surface area

$T_{h}$ : Hot surface temperature

$T_{c}$ : Cold surface temperature

$\Delta P_{\text {form }}$ : Pressure loss due to pipe form

$\Delta P_{\text {acc }}:$ Pressure loss due to acceleration

$\Delta P_{\text {fric }}:$ Pressure loss due to friction

$\Delta P_{\text {total }}$ : Total pressure loss.

Subscript

c: Coating

cc: Corroded coating (thermally and hydrogen exposed)

g: Graphite

cg: Corroded graphite.

\section{Conflicts of Interest}

The authors declare that there are no conflicts of interest regarding the publication of this paper.

\section{Acknowledgments}

The authors would like to thank the NASA Idaho Space Grant Consortium for supporting this research. In addition, the authors would also like to thank the Center for Space Nuclear 
Research personnel for providing materials helpful to this research.

\section{References}

[1] S. Gunn, "Nuclear propulsion-a historical perspective," Space Policy, vol. 17, no. 4, pp. 291-298, 2001.

[2] K. M. Akyuzlu, "Numerical Study of High-Temperature and High-Velocity Gaseous Hydrogen Flow in a Cooling Channel of a Nuclear Thermal Rocket Core," Journal of Nuclear Engineering and Radiation Science, vol. 1, no. 4, p. 041006, 2015.

[3] M. Russon, "NASA Cutting Mars Travel Time in Half Using Solar-Electric Engines and Nuclear Rockets," International Business Times, 2015, http://www.ibtimes.co.uk/nasa-cuttingmars-travel-time-half-using-solar-electric-engines-nuclearrockets-1504450.

[4] L. Summerer and K. Stephenson, "Nuclear power sources: A key enabling technology for planetary exploration," Proceedings of the Institution of Mechanical Engineers, Part G: Journal of Aerospace Engineering, vol. 225, no. 2, pp. 129-143, 2011.

[5] S. De Grandis, E. Finzi, C. Lombardi et al., "A feasibility study of an integral PWR for space applications," in Proceedings of the ICAPP, vol. 4, 2004, Pittsburgh, Pa, USA.

[6] E. Finzi, C. V. Lombardi, and L. Summerer, "An integrated PWR for planetary exploration," in Proceedings of the ICAPP, vol. 7, Nice, France, May 2007.

[7] M. Houts, "Space Fission Power and Propulsion," 2014, https:// ntrs.nasa.gov/archive/nasa/casi.ntrs.nasa.gov/20150002600.pdf.

[8] J. A. Peoples, "Malfunction Analysis of a Conceptual Space Power Fast-Spectrum Reactor," Tech. Rep. N-71-12568; NASATM-X-2057; E-5690, National Aeronautics and Space Administration, Cleveland, Ohio, USA, 1970, https://ntrs.nasa.gov/ archive/nasa/casi.ntrs.nasa.gov/19710003093.pdf.

[9] G. Kruger, "A Cermet Fuel Reactor for Nuclear Thermal Propulsion," Tech. Rep. N92-11096, 1991, https://ntrs.nasa.gov/archive/ nasa/casi.ntrs.nasa.gov/19920001878.pdf.

[10] E. Schmidt, O. Lazareth, and H. Ludewig, "Kinetic-a system code for analyzing nuclear thermal propulsion rocket engine transients," AIP Conference Proceedings, vol. 271, no. 3, pp. 13031308, 1993.

[11] J. Fittje and B. Schnitzler, "Evaluation of Recent Upgrades to the NESS (Nuclear Engine System Simulation) Code," in Proceedings of the 44th AIAA/ASME/SAE/ASEE Joint Propulsion Conference \& Exhibit, p. 4951, July 2008.

[12] C. R. Simmons, "Performance of WANL Supplied Fuel Elements in PEWEE-1," Tech. Rep. WANL-TME-1937, Westinghouse Electric Corp. Astronuclear Lab, Pittsburgh, Pa, USA, 1969, https://www.osti.gov/scitech/servlets/purl/4207386.

[13] J. Finseth, "Rover nuclear rocket engine program: Overview of rover engine tests. Final Report," Tech. Rep., Sverdrup Corporation for NASA MSFC, 1991, https://ntrs.nasa.gov/ archive/nasa/casi.ntrs.nasa.gov/19920005899.pdf.

[14] S. K. Borowski, D. R. McCurdy, and T. W. Packard, "Nuclear Thermal Propulsion (NTP): A proven growth technology for human NEO/Mars exploration missions," in Proceedings of the Aerospace Conference 2012, pp. 1-20, IEEE, Big Sky, Mont, USA, 3-10 March 2012.

[15] B. K. Heath and F. Aydogan, "Radiation Heat Transfer in the Fuel of a Nuclear Rocket," Journal of Thermal Engineering, vol. 2, no. 2, pp. 786-793, 2016.
[16] N. E. Todreas and M. S. Kazimi, Nuclear Systems Volume 1: Thermal Hydraulic Fundamentals, CRC Press, Boca Raton, Fla, USA, 2012.

[17] R. W. Jones and J. L. Crosthwaite, "Uranium Carbide Fuel for Organic Cooled Reactors," Tech. Rep. AECL-4443, Atomic Energy of Canada Limited, 1973, http://www.iaea.org/inis/ collection/NCLCollectionStore/_Public/05/137/5137806.pdf.

[18] Entegris, "Properties and Characteristics of Graphite," 2013, https://www.entegris.com/content/dam/web/resources/brochures/brochure-properties-and-characteristics-of-graphite7329.pdf.

[19] M. Woydt and H. Mohrbacher, "The tribological and mechanical properties of niobium carbides $(\mathrm{NbC})$ bonded with cobalt or Fe3Al," Wear, vol. 321, pp. 1-7, 2014.

[20] AZO Materials, "Zirconium Carbide," 2016, http://www.azom .com/properties.aspx?ArticleID=261http://www.azom.com/ properties.aspx?ArticleID=261.

[21] S. H. Nam, P. Venneri, Y. Kim, J. I. Lee, S. H. Chang, and Y. H. Jeong, "Innovative concept for an ultra-small nuclear thermal rocket utilizing a new moderated reactor," Nuclear Engineering and Technology, vol. 47, no. 6, pp. 678-699, 2015.

[22] E. Zolfagharifard, "NASA Wants to Use Nuclear Rockets to Get to Mars. Daily Mail," 2016, http://www.dailymail.co.uk/ sciencetech/article-3499441/Nasa-wants-use-nuclear-rocketsMars-Space-agency-claims-technique-effective-way-reachingred-planet.html. 


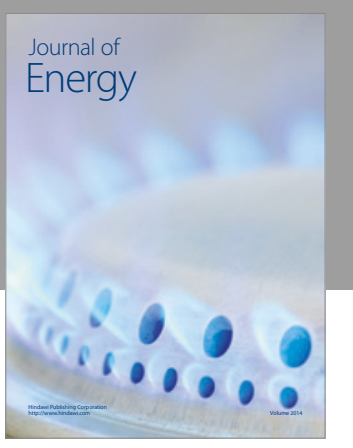

Journal of

Industrial Engineering
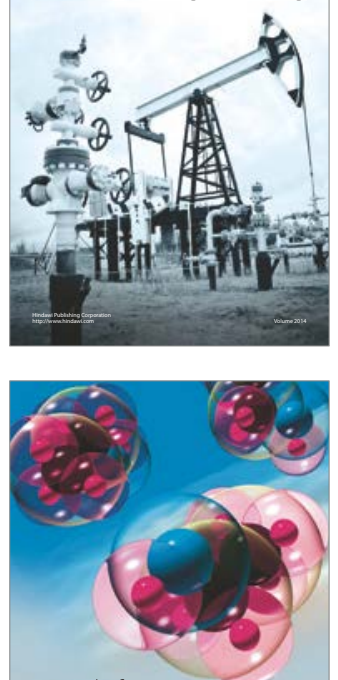

Fuels
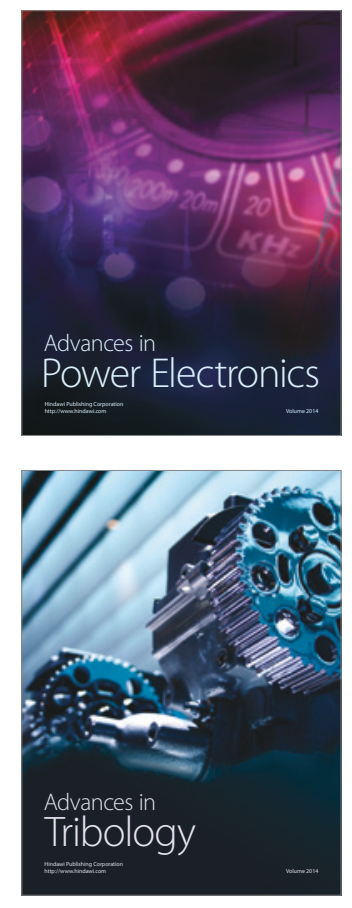
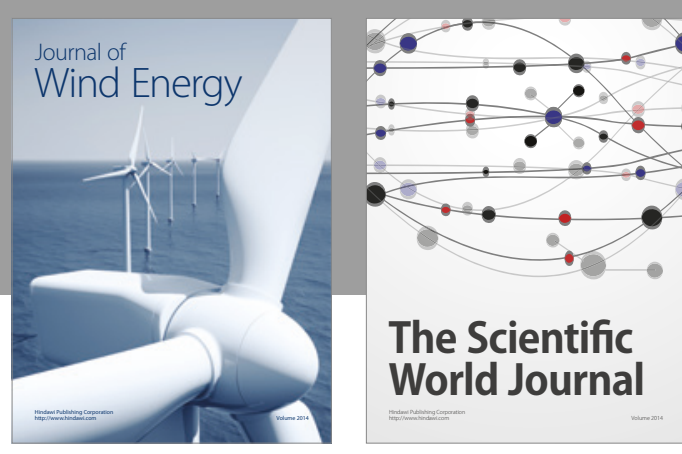

The Scientific World Journal
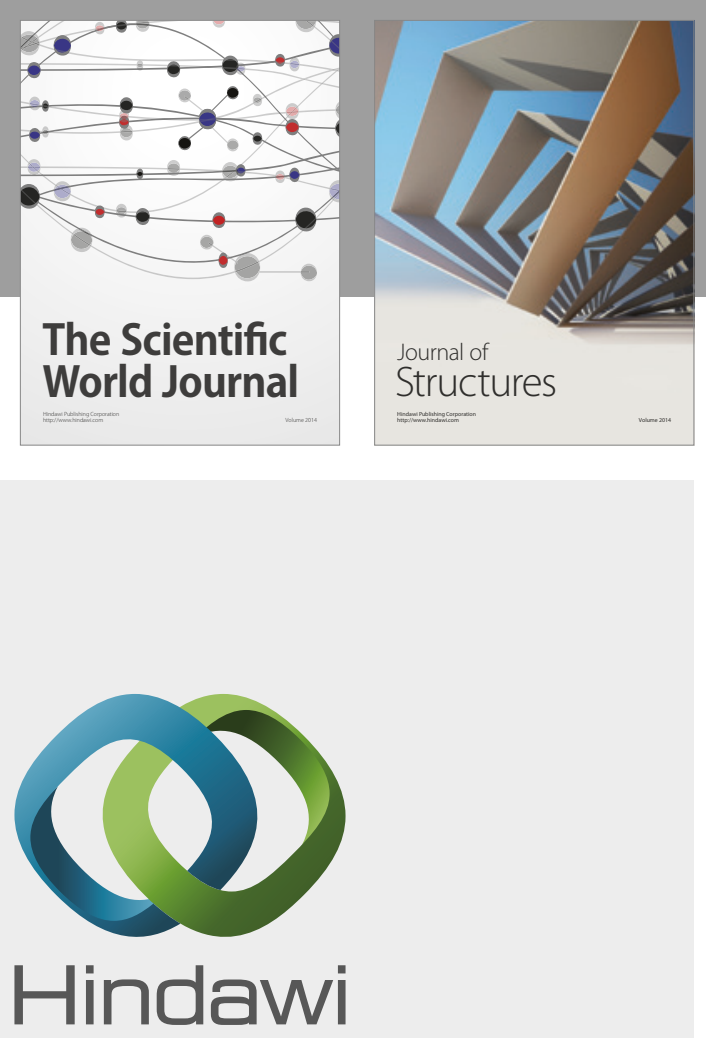

Submit your manuscripts at

https://www.hindawi.com
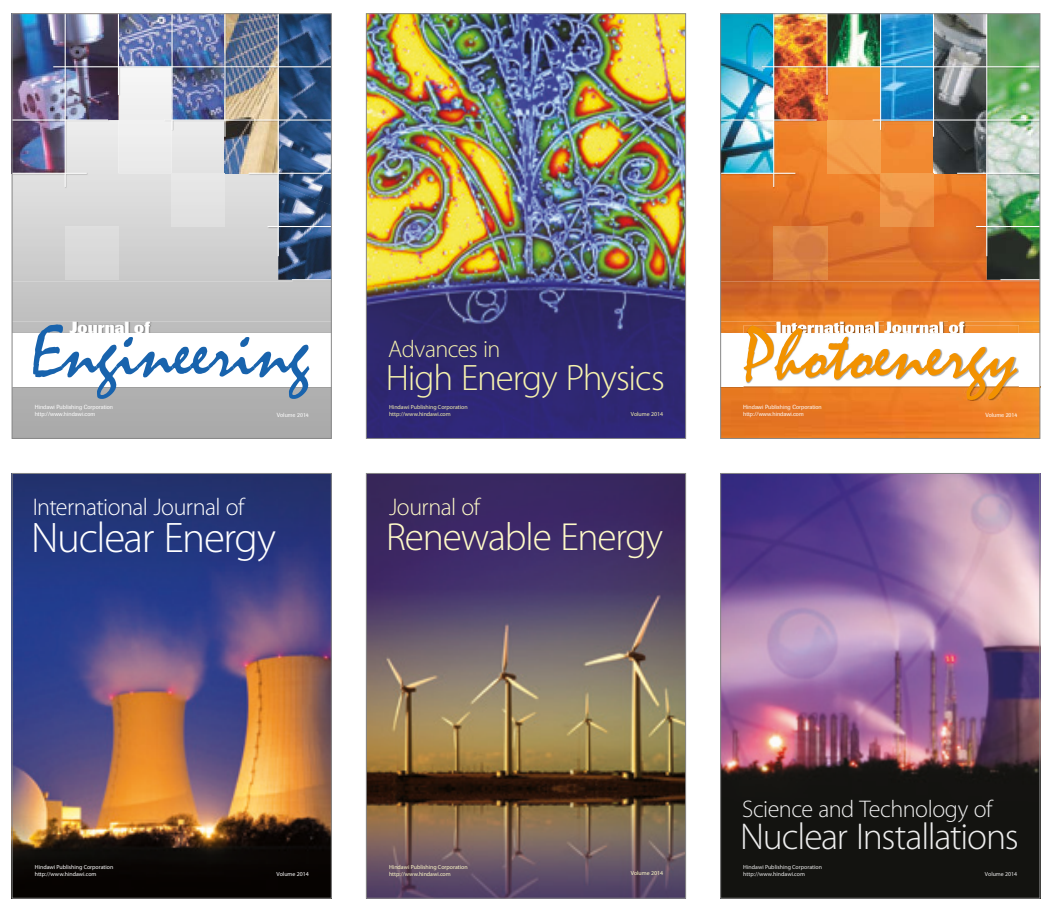

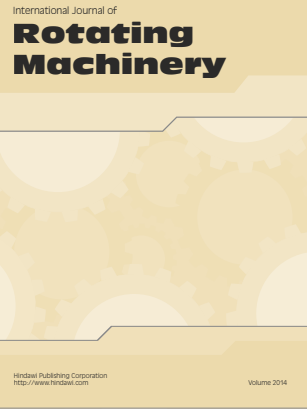

Journal of

Petroleum Engineering

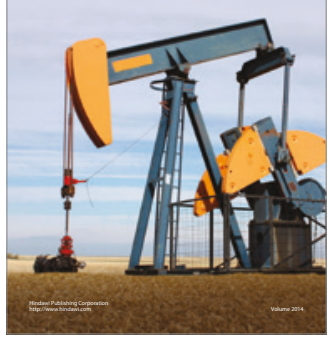

Journal of
Solar Energy
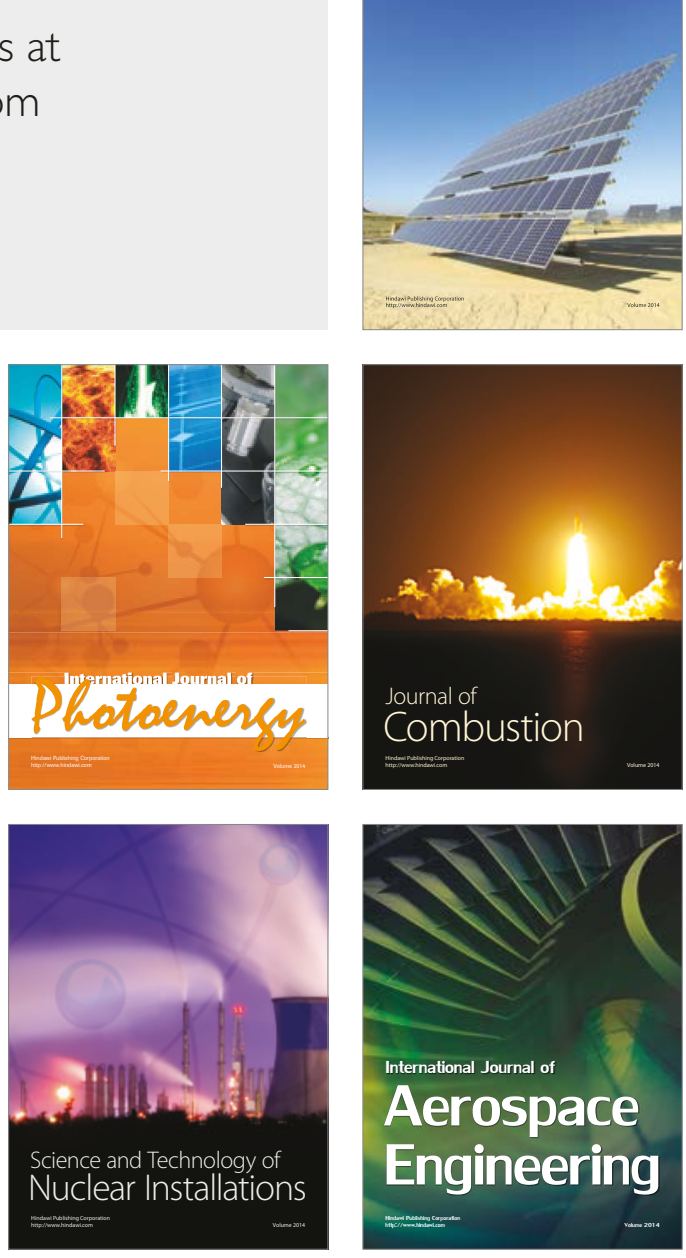